\title{
Q-Targeting in New Keynesian Models
}

\author{
Burkhard Heer $^{1,2}\left(\mathbb{D} \cdot\right.$ Alfred Maußner $^{1} \cdot$ Halvor Ruf $^{1}$
}

\begin{abstract}
We consider optimal monetary policy in a model that integrates credit frictions in the standard New Keynesian model with sticky prices and wages as well as adjustment costs of capital. Different from traditional models with credit frictions, such as those by Carlstrom and Fuerst (Econ Theory 12:583-597, 1998), our model is able to generate an anti-cyclical external finance premium as observed empirically in the U.S. economy. Monetary policy is characterized by a Taylor rule according to which the nominal interest rate is set as a function of the deviation of the inflation rate from its target rate, the output gap, and Tobin's q. The latter is measured by the relative price of newly installed capital. We show that monetary policy should optimally decrease interest rates with higher capital prices. However, the consideration of Tobin's q implies only small welfare effects. These results are robust with respect to a more general Epstein and Zin (Econometrica 57:937-969, 1989) welfare specification and to exogenous shifts to both the atemporal marginal rate of substitution between consumption and leisure as well as the households' discounting behavior.
\end{abstract}

Keywords Asset prices · Monetary policy · New Keynesian model · $\mathrm{Q}$ targeting

\section{JEL Classification E12 $\cdot$ E32 $\cdot$ E52 $\cdot$ G12}

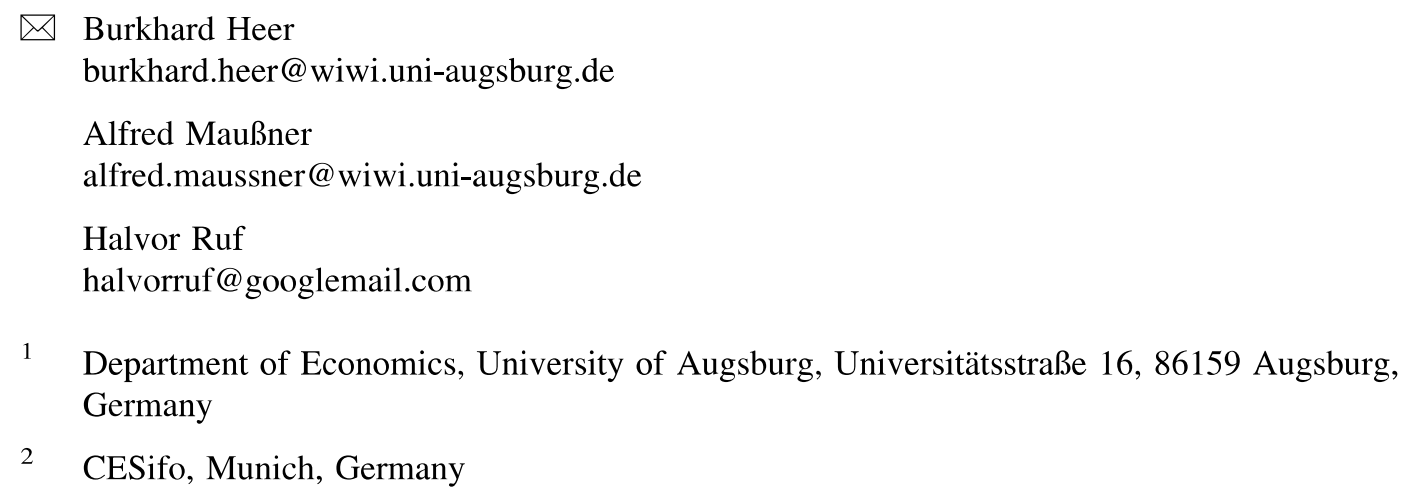




\section{Introduction}

The financial crisis of 2007 has triggered renewed interest into a debate which started in the late 1990s: should central banks target asset prices? Bernanke and Gertler $(1999,2001)$ were among the first to ask how central bankers should react to asset price volatility. They argue that there is no need for concern, if asset price movements reflect changes in economic fundamentals. However, if asset prices were driven by non-fundamental factors, their influence could be destabilizing. They consider a bursting asset price bubble in a version of the model developed in Bernanke et al. (1999) and show that asset price targeting may even destabilize the economy.

The more recent literature has contributed additional arguments in favor of or against asset price targeting. Gilchrist and Saito (2008) introduce imperfect information about the nature of technology shocks into the model of Bernanke et al. (1999) and employ a loss function with the variance of inflation and the variance of the output gap as arguments to assess monetary policy. A temporary positive shock to total factor productivity being partly considered as longer-lived impacts on inflation and the output gap via two distortions: the mark-up of prices on marginal costs and the financial accelerator. If the central bank reacts to inflation only, its impact on the fluctuations of output is limited as compared to a rule that changes the nominal interest rate also in response to the deviation of asset prices from their level in the frictionless economy. Christiano et al. (2010) study news driven cycles in a medium scale New Keynesian model with price and wage stickiness and the financial accelerator of Bernanke et al. (1999). News about a future improvement of factor productivity lowers expected marginal costs and reduces inflation. If the central bank responds by lowering the nominal interest it fuels an unwarranted boom. In order to moderate the effects of this kind of shock, the central bank should respond to the increased credit demand of borrowers and raise the nominal interest rate. Carlstrom and Fuerst (2007) argue that asset price targeting may increase the parameter region within which the rational expectations equilibrium is not unique so that sunspot equilibria arise. Machado (2012) considers learning in the model of Carlstrom and Fuerst (2007) and shows that asset price targeting may hamper the convergence to the rational expectations equilibrium.

While these papers focus on particular effects of asset price targeting, Faia and Monacelli (2007) adopt a welfare economics approach. They rank different Taylor rules with and without an indicator of asset price movements according to the associated expected life-time utility of the representative agent. Their framework is the financial accelerator model of Carlstrom and Fuerst (1997) amended with quadratic costs of price adjustment. The interaction between the nominal friction and the financial friction requires a negative response of the nominal interest rate set by the central bank and the relative price of capital. Moreover, the welfare gains of targeting the price of capital in addition to inflation are very small as compared to a strict anti-inflation policy.

In this paper, we also consider the desirability of asset price targeting with respect to its effect on the welfare of the representative household. Our study is most 
closely related to Faia and Monacelli (2007). With regard to the methodology, we employ the approach pioneered by Schmitt-Grohé and Uribe $(2005,2007)$ and compute the welfare effects of an extended Taylor rule relative to a simple Taylor rule that just reacts to the deviation of inflation from the central bank's target. As Schmitt-Grohé and Uribe $(2005,2007)$ we disregard rules that i) lead to indeterminacy and ii) may hurt the zero lower bound. As Faia and Monacelli (2007) we consider Taylor rules with four arguments: the one period lagged nominal interest rate, the deviation of inflation from target inflation, the deviation of output from its steady state level, and the relative price of capital goods as an indicator of asset prices. In the parlance of Schmitt-Grohe and Uribe $(2005,2007)$ this rule is implementable, since the central bank reacts to observable variables only. Different from Faia and Monacelli (2007), we consider i) both additively separable and nonseparable preferences and ii) a richer structure of shocks as a reduced form of capturing market incompleteness and saving behavior in presence of possible severe economic downturns as described in the Gourio (2012) disaster framework. In addition, iii) we merge adjustment costs of capital and financial frictions so that our model is closer in spirit to Bernanke et al. (1999). The financial friction which we consider follows Carlstrom and Fuerst (1998). They assume that the producers of goods must pay their factors of production in advance. The credit contract imposes liquidation costs that the producers pass on to the suppliers of factor services via an (inverse) mark-up on factor costs. The credit costs decrease with increasing net wealth of the producers. The net wealth, in turn, raises with the price of capital, i.e., Tobin's q. Therefore, the inclusion of asset prices in the central bank's decision rule has the potential to improve monetary policy. ${ }^{1}$

The paper is structured as follows. In the next section, we introduce a first model with the usual shock to total factor productivity and a government spending shock. The model features two nominal frictions (price and wage staggering as in Calvo (1983)) and a financial friction in the production of primary goods as proposed by Carlstrom and Fuerst (1998). Section 3 presents the calibration of the model. In Sect. 4, we present our results. Section 5 studies the robustness of these results with respect to the specification of the household's preferences and with respect to the interaction of supply and demand shocks. The main conclusion of Faia and Monacelli (2007) remains intact in all our setups: the welfare gain of targeting the relative price of capital are negligible. Section 6 concludes.

\section{The Model}

The basic model merges a standard New Keynesian model with sticky nominal prices and wages as, e.g., in Erceg et al. (2000) and Christiano et al. (2005), and adjustment costs of capital as, e.g., in Jermann (1998) and Bernanke et al. (1999) with the credit friction model of Carlstrom and Fuerst (1998).

\footnotetext{
1 This mechanism is missing in the model of Cúrdia and Woodford (2016) who abstract from capital and focus on credit spreads in a model of heterogenous households.
} 


\subsection{Structure of the Model}

The model consists of a household with a unit mass of members indexed by $h$, the government, a labor agency, a sector with a unit mass of primary goods producers indexed by $f$, a wholesale sector with a unit mass of monopolistically competitive firms indexed by $j$, a final goods sector, and a capital goods producing sector. Time is discrete and denoted by $t$. Figure 1 illustrates the flows of factor services and goods between the household and the various sectors of the economy.

The members of the household rent their labor services $N_{h t}$ to the labor agency which sells a composite $N_{t}$ of these services to the primary goods producers. In addition to labor each firm $f$ in this sector also rents capital services from the household sector $K_{H t}$ and from other firms $X_{t}$ to produce $\tilde{Y}_{f t}$ units of a good, which serves as input in the production of intermediary goods. Each firm $j \in[0,1]$ in this sector produces a differentiated good $Y_{j t}$ and sells it to the final goods sector. This sector bundles the intermediary goods and sells consumption goods $C_{t}$ to the household, investment goods $I_{t}$ to the capital goods sector and public goods $G_{t}$ to the government. New capital goods are produced from capital services, rented from the household and primary goods producers and from investment goods. They are sold to primary goods producers, $X_{t+1}-(1-\delta) X_{t}$, and to the household, $K_{H t+1}-(1-\delta) K_{H t}$.

\subsection{Final Goods}

The firm in this sector buys the brands $Y_{j t}, j \in[0,1]$ at the nominal price $P_{j t}$ from the intermediary goods sector and combines them to a final good $Y_{t}$, which is sold at the nominal price $P_{t}$ to the household as consumption good $C_{t}$, to the capital goods production sector as investment good $I_{t}$, and to the government, $G_{t}$. The technology is given by

$$
Y_{t}=\left[\int_{0}^{1} Y_{j t}^{\frac{\epsilon y-1}{\epsilon_{y}}} d j\right]^{\frac{\epsilon y}{y_{y}-1}}, \quad \epsilon_{y}>1 .
$$

Profit maximization implies the usual demand function for intermediary good $j$ :

$$
Y_{j t}=\left(\frac{P_{j t}}{P_{t}}\right)^{-\epsilon_{y}} Y_{t},
$$

where the price index $P_{t}$ is given by

$$
P_{t}=\left(\int_{0}^{1} P_{j t}^{1-\epsilon_{y}} d j\right)^{\frac{1}{1-\epsilon_{y}}},
$$

so that profits are equal to zero:

$$
0=P_{t} Y_{t}-\int_{0}^{1} P_{j t} Y_{j t} d j .
$$




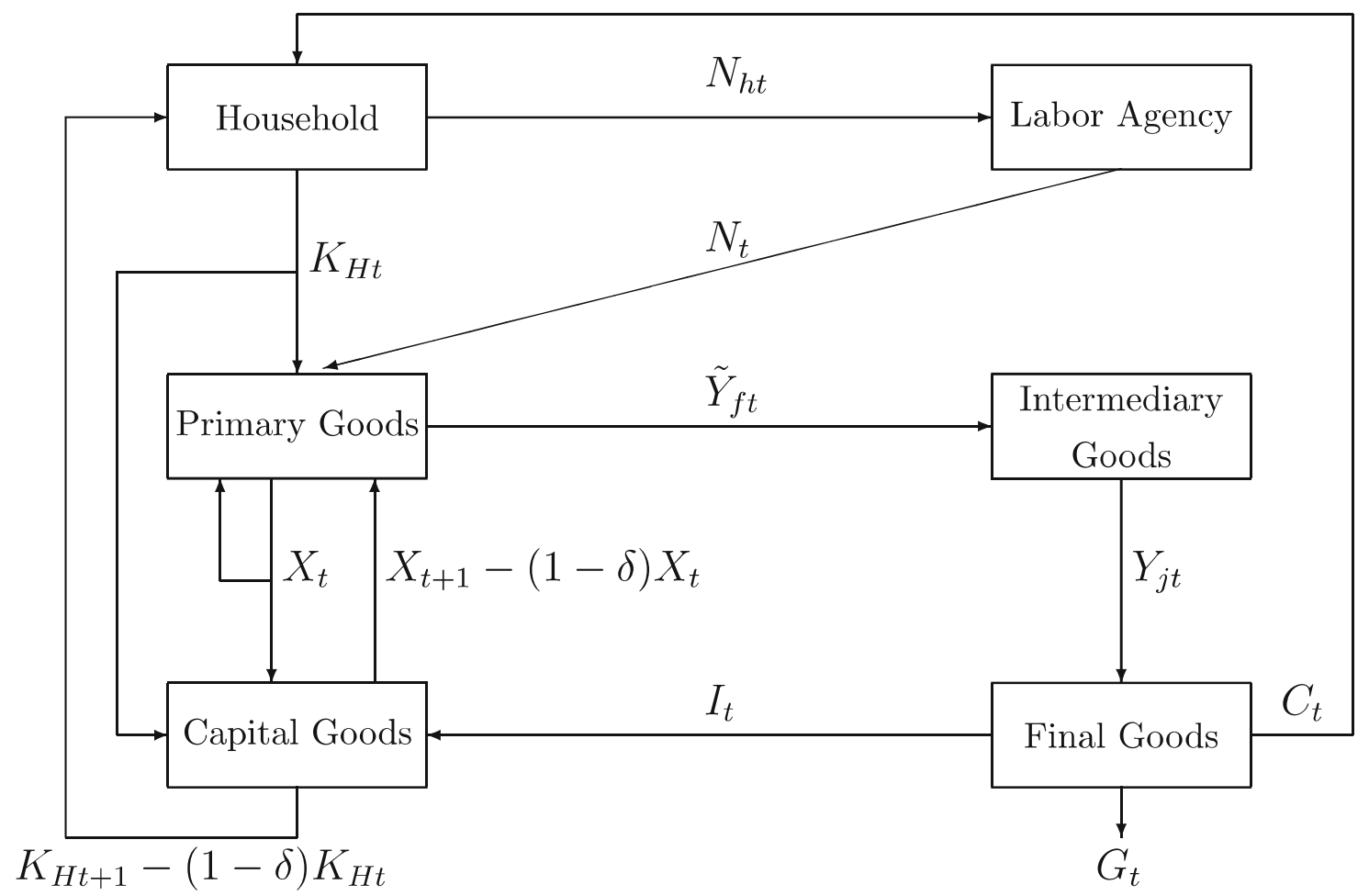

Fig. 1 Structure of the model

\subsection{Capital Goods}

We implement adjustment costs of capital as in Bernanke et al. (1999). Capital goods depreciate at the rate $\delta$ and new capital goods are produced from capital services $K_{t}=K_{H t}+X_{t}$ rented at the price $r_{K t}$ and from investment goods $I_{t}$ according to the function $\Psi\left(I_{t} / K_{t}\right) K_{t}$. They are sold at the price $q_{t}$. The function $\Psi(x), x:=I_{t} / K_{t}$ is increasing in its argument $x$ and concave. As usual, we assume that it is costless to keep the capital stock constant, i.e., at the point $x=\delta$ the function value is equal to $\Psi(\delta)=\delta$ and the first derivative is equal to $\Psi^{\prime}(\delta)=1$. In our numerical simulations we follow Jermann (1998) and employ the functional form

$$
\Psi\left(I_{t} / K_{t}\right)=\frac{a_{1}}{1-\zeta}\left(\frac{I_{t}}{K_{t}}\right)^{1-\zeta}+a_{2}, \quad \zeta \in \mathbb{R}_{\geq 0} \backslash\{1\}
$$

Profit maximization,

$$
\max _{K_{t}, I_{t}} \quad q_{t} \Psi\left(I_{t} / K_{t}\right) K_{t}-r_{K t} K_{t}-I_{t}
$$

implies

$$
\begin{aligned}
& q_{t}=\frac{1}{\Psi^{\prime}\left(I_{t} / K_{t}\right)} \\
& r_{K t}=q_{t} \Psi\left(I_{t} / K_{t}\right)-\left(I_{t} / K_{t}\right)
\end{aligned}
$$


so that profits are zero in equilibrium.

\subsection{Intermediary Goods and Price Setting}

A firm $j \in[0,1]$ in the intermediary sector buys goods at the nominal price $P_{y t}$ from the primary production sector, brands it and sells it at the price $P_{j t}$ to the final goods sector. Its profit in units of the final product equals

$$
D_{j t}^{I}=\left(\frac{P_{j t}}{P_{t}}-g_{t}\right) Y_{j t}, \quad g_{t}:=\frac{P_{y t}}{P_{t}}
$$

and is distributed to the household sector. We apply the Calvo (1983) mechanism for sticky price setting: In each period $t$, a randomly selected fraction $1-\varphi_{y}$ of firms in this sector receives the signal to optimally choose their price $P_{A t}$ and thus their relative price $p_{A t}:=P_{A t} / P_{t}$. The remaining fraction is allowed to raise their nominal price $P_{N t}$ according to the inflation rate $\pi_{t}-1$ observed in the previous period:

$$
P_{N t}=\pi_{t-1} P_{N t-1}, \quad \pi_{t}:=\frac{P_{t}}{P_{t-1}}
$$

\subsection{Primary Production}

Primary production is organized in a sector with a unit mass of firms $f \in[0,1]$. In Carlstrom and Fuerst (1998) these firms are owned by risk-neutral entrepreneurs. We follow Chugh (2013) and assume that the household owns the firms but that firms are more impatient than the household. This reflects an un-modeled principal agent problem that drives a wedge between the interest of the household and the management of the firm. Its effect is to prevent full self-financing of firms (see Carlstrom and Fuerst 1997).

Firm Assets. The firms need credit to pay for their factor services in advance. In order to get credit they have to accumulate assets. Let $X_{f t}$ denote the stock of capital owned by firm $f$ at the beginning of period $t$. The firm rents this capital at the price $r_{Y t}$ to other primary goods producing firms. When production in this sector has taken place it rents the same amount to the capital goods sector at the rate $r_{K t}$. In addition to its factor income the firm receives a small transfer $\Delta_{f t}$ from the household. This ensures that the firm will be able to continue operating even in the case of credit default. The transfer is deducted from the firm's dividend payment to the household. The net worth $N W_{f t}$ of the firm, therefore, is equal to

$$
N W_{f t}=\left(q_{t}(1-\delta)+r_{Y t}+r_{K t}\right) X_{f t}+\Delta_{f t} .
$$

Production and Factor Demand. The firm $f$ employs labor $N_{f t}$ and capital $K_{f t}$ to produce the amount

$$
\tilde{Y}_{f t}=\omega_{f t} Z_{t} N_{f t}^{1-\alpha} K_{f t}^{\alpha}, \quad \alpha \in(0,1),
$$


where $\omega_{f t}$ is the firm specific realization of an idiosyncratic shock $\omega_{t}$, distributed independently of the firm index $f$ and identically over time $t$ with density $\phi\left(\omega_{t}\right)$ and mean $\mathbb{E}\left(\omega_{t}\right)=\Omega_{t}$. $Z_{t}$ is an aggregate technology shock that is governed by

$$
\ln Z_{t}=\rho_{Z} \ln Z_{t-1}+\epsilon_{Z t}, \quad \rho_{Z} \in[0,1), \epsilon_{Z t} \sim \operatorname{iid~N}\left(0, \sigma_{Z}^{2}\right) .
$$

The firm must pay the real amount $M_{f t}$ for its factor services in advance. It observes $Z_{t}$ but not $\omega_{f t}$ before it decides on the size of its credit $M_{f t}-N W_{f t}$. After it has observed $\omega_{f t}$ the firm maximizes its revenue

$$
g_{t} \omega_{f t} Z_{t} N_{f t}^{1-\alpha} K_{f t}^{\alpha}
$$

subject to $M_{f t} \geq w_{t} N_{f t}+r_{Y t} K_{f t}$, where $w_{t}$ denotes the wage rate in units of the final good. The first-order conditions

$$
\begin{aligned}
& \lambda_{f t} w_{t}=(1-\alpha) g_{t} \omega_{f t} Z_{t} N_{f t}^{-\alpha} K_{f t}^{\alpha}, \\
& \lambda_{f t} r_{Y t}=\alpha g_{t} \omega_{f t} Z_{t} N_{f t}^{1-\alpha} K_{f t}^{\alpha-1}
\end{aligned}
$$

imply $w_{t} / r_{Y t}=((1-\alpha) / \alpha)\left(K_{f t} / N_{f t}\right)$ so that all firms employ the same capital-laborratio $k_{t}:=\left(K_{f t} / N_{f t}\right)$. As a consequence, the scaled Lagrange multiplier of the constraint $v_{t}:=\lambda_{f t} / \omega_{f t}$ is independent of the firm index $f$, and

$$
v_{t} M_{f t}=g_{t} Z_{t} N_{f t}^{1-\alpha} K_{f t}^{\alpha}=g_{t} Z_{t} k_{t}^{\alpha} N_{f t} .
$$

Thus, in terms of the final good, $v_{t}$ is a mark-up on factor costs $M_{f t}$. For later reference note that $(2.11)$ can be integrated to:

$$
v_{t} M_{t}=g_{t} Z_{t} k_{t}^{\alpha} N_{t}
$$

and that the first-order conditions for factor demand can be written in terms of aggregate variables only:

$$
\begin{aligned}
& w_{t}=(1-\alpha)\left(g_{t} / v_{t}\right) \tilde{Y}_{t} / N_{t}, \\
& r_{Y t}=\alpha\left(g_{t} / v_{t}\right) \tilde{Y}_{t} / K_{t}, \\
& \tilde{Y}_{t}=Z_{t} N_{t}^{1-\alpha} K_{t}^{\alpha},
\end{aligned}
$$

where $x_{t}=\int_{0}^{1} x_{f t} d f$, for $x \in\{K, M, N, \tilde{Y}\}$. Since both $M_{f t}$ and $k_{t}$ are independent of the realization of $\omega_{f t}$, Eq. (2.11) also implies that $N_{f t}$ is independent of the idiosyncratic shock. This allows us to compute the aggregate output of the primary sector: ${ }^{2}$

$$
\int_{0}^{1} \omega_{f t} Z_{t} N_{f t}^{1-\alpha} K_{f t}^{\alpha} d f=Z_{t} k_{t}^{\alpha} \int_{0}^{1} \omega_{f t} N_{f t} d f=Z_{t} k_{t}^{\alpha} \Omega_{t} N_{t}=\Omega_{t} \tilde{Y}_{t} .
$$

\footnotetext{
${ }^{2}$ The last part of the equation follows from the independence of $\omega_{f t}$ and $N_{f t}$, so that $\int_{0}^{1} \omega_{f} N_{f} d f=\int_{0}^{1} N_{f} d f \int_{0}^{1} \omega_{f} d f$, and from a law of large numbers, i.e., $\int_{0}^{1} \omega_{f} d f=\mathbb{E}\left(\omega_{f}\right) \equiv \Omega$.
} 
The Credit Contract. The firm borrows the amount $M_{f t}-N W_{f t}$ intra-periodically from the household. The realization of $\omega_{f t}$ is private information. If the creditor wishes to see the firm's production, he must pay a screening cost. This cost is assumed to be proportional to marked-up real factor costs in terms of the final good $v_{t} M_{f t}$ with factor of proportionality $\kappa$. This is the costly state verification framework of Townsend (1979), Gale and Hellwig (1985), and Williamson (1987) as employed in Carlstrom and Fuerst $(1997,1998)$.

The credit contract specifies $M_{f t}$, the lending rate $r_{L t}$, and a bankruptcy threshold $\bar{\omega}_{f t}$, given by

$$
\bar{\omega}_{f t}:=\left(1+r_{L t}\right) \frac{M_{f t}-N W_{f t}}{g_{t} Z_{t} N_{f t}^{1-\alpha} K_{f t}^{\alpha}},
$$

so that for $\omega_{f t}<\bar{\omega}_{f t}$ firm $f$ defaults and the creditor seizes the firm's output less the screening costs. Otherwise the firm redeems the loan, pays the interest and keeps all of its production. Because the household lends to all firms, he can fully diversify the risk and acts as if he was risk-neutral. The expected return for the firm equals

$$
\begin{aligned}
& \int_{\bar{\omega}_{f t}} \omega_{t} g_{t} Z_{t} N_{f t}^{1-\alpha} K_{f t}^{\alpha} \phi\left(\omega_{t}\right) d \omega_{t}-\left(1-\Phi\left(\bar{\omega}_{f t}\right)\right)\left(1+r_{L t}\right)\left(M_{f t}-N W_{f t}\right), \\
& \Phi\left(\bar{\omega}_{f t}\right)=\int^{\bar{\omega}_{f t}} \phi\left(\omega_{t}\right) d \omega_{t} .
\end{aligned}
$$

Using (2.15) this expression can be written as $g_{t} Z_{t} N_{f t}^{1-\alpha} K_{f t}^{\alpha} f\left(\bar{\omega}_{f t}\right)$, where

$$
f\left(\bar{\omega}_{f t}\right)=\int_{\bar{\omega}_{f t}} \omega_{t} \phi\left(\omega_{t}\right) d \omega_{t}-\left(1-\Phi\left(\bar{\omega}_{f t}\right)\right) \bar{\omega}_{f t}
$$

Note that from (2.11) the expected return to the borrower can also be written as a fraction $h\left(\bar{\omega}_{f t}\right)$ of the factor costs. The expected return of the creditor equals

$$
\int^{\bar{\omega}_{f t}} \omega_{t} g_{t} Z_{t} N_{f t}^{1-\alpha} K_{f t}^{\alpha} \phi\left(\omega_{t}\right) d \omega_{t}+\left(1-\Phi\left(\bar{\omega}_{f t}\right)\right)\left(1+r_{L t}\right)\left(M_{f t}-N W_{f t}\right)-\Phi\left(\bar{\omega}_{f t}\right) \kappa v_{t} M_{f t} .
$$

Using (2.15) and (2.13c), the expected return is equal to $v_{t} M_{f t} h\left(\bar{\omega}_{t}\right)$ with

$$
h\left(\bar{\omega}_{f t}\right)=\int^{\bar{\omega}_{f t}} \omega_{t} \phi\left(\omega_{t}\right) d \omega_{t}+\left(1-\Phi\left(\bar{\omega}_{f t}\right)\right) \bar{\omega}_{f t}-\Phi\left(\bar{\omega}_{f t}\right) \kappa .
$$

Finally, note that

$$
f\left(\bar{\omega}_{f t}\right)+h\left(\bar{\omega}_{f t}\right)=\Omega_{t}-\Phi\left(\bar{\omega}_{f t}\right) \kappa .
$$

The optimal pair $\left(M_{f t}, \bar{\omega}_{f t}\right)$ maximizes the expected return of the firm $v_{t} M_{f t} f\left(\bar{\omega}_{t}\right)$ subject to the participation constraint of the household. Since the loan is intraperiod, the household will be indifferent between lending to a producer or keeping his funds, if he will at least get back his loan: $v_{t} M_{f t} h\left(\bar{\omega}_{t}\right) \geq M_{f t}-N W_{f t}$. This optimal pair thus solves 


$$
\begin{aligned}
1 & =v_{t}\left[\Omega_{t}-\Phi\left(\bar{\omega}_{f t}\right) \kappa-\frac{f\left(\bar{\omega}_{f t}\right) \phi\left(\bar{\omega}_{f t}\right) \kappa}{1-\Phi\left(\bar{\omega}_{f t}\right)}\right], \\
M_{f t} & =\frac{N W_{f t}}{1-v_{t} h\left(\bar{\omega}_{f t}\right)} .
\end{aligned}
$$

The first condition determines the bankruptcy threshold as a function of the markup on factor costs $v_{t}$. Since the share $f\left(\bar{\omega}_{f t}\right)$ depends only on the (cumulative) probability density function, all firms face the same threshold $\bar{\omega}_{t}$. Thus, the second condition can be aggregated over all firms in the primary production sector. As a consequence:

$$
\begin{gathered}
1=v_{t}\left[\Omega_{t}-\Phi\left(\bar{\omega}_{t}\right) \kappa-\frac{f\left(\bar{\omega}_{t}\right) \phi\left(\bar{\omega}_{t}\right) \kappa}{1-\Phi\left(\bar{\omega}_{t}\right)}\right], \\
M_{t}=\frac{N W_{t}}{1-v_{t} h\left(\bar{\omega}_{t}\right)} .
\end{gathered}
$$

Eventually, Eqs. (2.11) and (2.19b) imply that the external finance premium $r_{L t}$ in Eq. (2.15) is determined by

$$
r_{L t}=\frac{\bar{\omega}_{t}}{h\left(\bar{\omega}_{t}\right)}-1
$$

Asset Accumulation of the Firm. We assume that the firm $f$ distributes

$$
D_{f t}^{P}=v_{t} M_{f t} f\left(\bar{\omega}_{t}\right)-\Delta_{f t}-q_{t} X_{f t+1}
$$

as dividends to the household. As we shall demonstrate subsequently, the household's discount factor for returns from period $t+s$ is equal to $\beta^{s} \Lambda_{t+s} / \Lambda_{t}$, where $\Lambda_{t}$ is the multiplier of the household's budget constraint. The firm is more impatient than the household and employs the discount factor $(\beta \gamma)^{s} \Lambda_{t+s} / \Lambda_{t}$ with $\gamma \in(0,1)$. Therefore, the value of the firm is given by

$$
\mathbb{E}_{t} \sum_{s=0}^{\infty}(\gamma \beta)^{s} \frac{\Lambda_{t+s}}{\Lambda_{t}} D_{f t+s}^{P}
$$

Substituting for $D_{f t}^{P}$ from (2.21), for $M_{f t}$ from (2.19b), and for $N W_{f t}$ from (2.8) and maximizing with respect to $X_{f t+1}$ yields the Euler equation

$$
q_{t}=\gamma \beta \mathbb{E}_{t} \frac{\Lambda_{t+1}}{\Lambda_{t}}\left[q_{t+1}(1-\delta)+r_{Y t+1}+r_{K t+1}\right] \frac{v_{t+1} f\left(\bar{\omega}_{t+1}\right)}{1-v_{t+1} h\left(\bar{\omega}_{t+1}\right)} .
$$

\subsection{Labor Demand}

The household has a unit mass of members $h \in[0,1]$ who sell their labor services $N_{h t}$ at the wage rate $W_{h t}$ to an agency. The agency bundles them into a single service, 


$$
N_{t}=\left[\int_{0}^{1} N_{h t}^{\frac{\epsilon_{n}-1}{\epsilon_{n}}} d h\right]^{\frac{\epsilon_{n}}{\epsilon_{n}-1}}, \quad \epsilon_{n}>1
$$

and sells this service at the nominal wage $W_{t}$ to the primary goods producers. Profit maximization implies the demand function

$$
N_{h t}=\left(\frac{W_{h t}}{W_{t}}\right)^{-\epsilon_{n}} N_{t}
$$

where the wage index $W_{t}$ is given by

$$
W_{t}=\left[\int_{0}^{1} W_{h t}^{1-\epsilon_{n}}\right]^{\frac{1}{1-\epsilon_{n}}}
$$

so that the agency's profit are equal to zero:

$$
0=W_{t} N_{t}-\left(\int_{0}^{1} W_{h t} N_{h t} d h\right)
$$

\subsection{Wage Setting}

The current period utility $u$ of household member $h$ depends on his consumption $C_{h t}$, labor supply $N_{h t}$ and the consumption habit $\mathscr{C}_{t}$. We parameterize $u$ as follows:

$$
u\left(C_{h t}, N_{h t}\right)=\frac{\left(C_{h t}-\mathscr{C}_{t}\right)^{1-\eta}-1}{1-\eta}-\frac{v_{0}}{1+v_{1}} N_{h t}^{1+v_{1}}, \quad \eta, v_{0}, v_{1} \geq 0,
$$

where $\mathscr{C}_{t}:=\chi C_{t-1}, \chi \in[0,1)$. In equilibrium, $\mathscr{C}_{t}$ thereby equals a fraction $\chi$ of previous period's aggregate consumption $C_{t-1}=\int_{0}^{1} C_{h t-1} d h$.

We again apply the Calvo (1983) framework, i.e. in each period a random fraction $1-\varphi_{n}$ of the household members receive a signal to choose their nominal wage $W_{A t}$ optimally. The remaining fraction $\varphi_{n}$ is allowed to increase their wage $W_{N t}$ according to the price inflation observed in the previous period:

$$
W_{N t}=\pi_{t-1} W_{N t-1}, \quad \pi_{t}=\frac{P_{t}}{P_{t-1}} .
$$

Those who receive a signal choose the optimal real wage $\tilde{w}_{t}:=W_{A t} / P_{t}$ to maximize their individual (standard) lifetime utility

$$
\mathbb{E}_{t} \sum_{s=0}^{\infty}\left(\beta \varphi_{n}\right)^{s} u\left(C_{h t+s}, N_{h t+s}\right)
$$

subject to labor demand (2.24) and the budget constraint

$$
\frac{W_{h t}}{P_{t}} N_{h t}+R M T_{t} \geq 0,
$$


where $R M T_{t}$ is a stand-in for the remaining terms of this constraint, which are independent of the optimal wage and will be introduced in the next subsection.

\subsection{Consumption and Portfolio Allocation}

As usual we assume that the members of the household pool their income so that their decision to consume and save is subject to a budget constraint in which we can ignore the index $h$. The representative household owns two different kinds of assets: ${ }^{3}$ nominal bonds $B_{t}$ and physical capital $K_{H t}$. The former pays the predetermined nominal interest rate $Q_{t}-1$. The latter yields a factor income of $\left(r_{Y t}+r_{K t}\right) K_{H t}$ because capital is first employed in the production of primary goods and subsequently in the production of capital goods. In addition to interest income, rental income, and wage income $w_{t} N_{t}$, the household receives dividends from the primary goods producers $\int D_{f t}^{I} d f$ and dividends from the intermediary goods producers $\int D_{j t}^{P} d j$. He pays taxes $T_{t}$ to the government and spends the remaining income on consumption $C_{t}$ and asset accumulation. His budget constraint in terms of the final good, therefore, reads:

$$
\begin{aligned}
& w_{t} N_{t}+\left(r_{Y t}+r_{K t}\right) K_{H t}+\int_{0}^{1} D_{j t}^{P} d j+\int_{0}^{1} D_{f t}^{I} d f+\left(Q_{t}-1\right) \frac{B_{t}}{P_{t}}-T_{t} \\
& \geq C_{t}+q_{t}\left(K_{H t+1}-(1-\delta) K_{H t}\right)+\frac{B_{t+1}-B_{t}}{P_{t}} .
\end{aligned}
$$

In our basic framework, per capita consumption $C_{h t}=C_{t}$, the future stock of capital $K_{H t+1}$, and optimal bond holdings $B_{t+1}$ are determined from maximizing the (standard) welfare specification

$$
\mathbb{E}_{t} \sum_{s=0}^{\infty} \beta^{s} \int_{0}^{1} u\left(C_{h t+s}, N_{h t+s}\right) d h
$$

subject to the budget constraint (2.28). The respective first-order conditions are

$$
\begin{gathered}
\Lambda_{t}=\left(C_{t}-\mathscr{C}_{t}\right)^{-\eta} \\
q_{t}=\beta \mathbb{E}_{t} \frac{\Lambda_{t+1}}{\Lambda_{t}}\left(q_{t+1}(1-\delta)+r_{Y t+1}+r_{K t+1}\right) \\
1=\beta \mathbb{E}_{t} \frac{\Lambda_{t+1}}{\Lambda_{t}} \frac{Q_{t+1}}{\pi_{t+1}}
\end{gathered}
$$

\subsection{Government}

The government's budget constraint reads:

\footnotetext{
3 In addition, he lends intra-periodically to firms in the primary sector. Since - as noted above - he receives his loan back at the end of the period, we ignore the loan in the budget constraint.
} 


$$
\frac{B_{t+1}-B_{t}}{P_{t}}+T_{t}=\left(Q_{t}-1\right) \frac{B_{t}}{P_{t}}+G_{t} .
$$

We assume $B_{t}=0$ for all $t$ and that government spending $G_{t}$ is exogenously governed by

$$
\ln G_{t}=\left(1-\rho_{G}\right) \ln G+\rho_{G} \ln G_{t-1}+\epsilon_{G t}, \quad \rho_{G} \in[0,1), \epsilon_{G t} \sim \operatorname{iid} \mathrm{N}\left(0, \sigma_{\mathrm{G}}^{2}\right) .
$$

\subsection{Monetary Authority}

The central bank sets the nominal interest rate $Q_{t+1}$ according to a Taylor rule. We specify the rule in accordance with Faia and Monacelli (2007) as an implementable rule, whose arguments are observable variables. These include the previously set interest rate $Q_{t}$ to account for sluggish adjustment, the deviation of the inflation factor $\pi_{t}$ from the target $\pi$, the deviation of Tobin's q $\left(q_{t}\right)$ from its (efficient) steady state value of $q=1$, and the deviation of output $Y_{t}$ from its stationary level $Y$ :

$$
Q_{t+1}=Q_{t}^{\vartheta_{1}}\left(\frac{\pi}{\beta}\right)^{1-\vartheta_{1}}\left(\frac{\pi_{t}}{\pi}\right)^{\vartheta_{2}}\left(q_{t}\right)^{\vartheta_{3}}\left(Y_{t} / Y\right)^{\vartheta_{4}}, \quad \vartheta_{1} \in[0,1) .
$$

The choice of the parameters $\vartheta_{2}, \vartheta_{3}$, and $\vartheta_{4}$ must satisfy two requirements: (i) the equilibrium dynamics of the economy must be determinate and (ii) the Taylor rule is subject to the zero lower bound, i.e. $Q_{t} \geq 1$. It is well-known that the former requires a coefficient on the inflation gap $\pi_{t} / \pi$ of $\vartheta_{2}>1$. This condition is independent of the value of the other parameters $\vartheta_{1}, \vartheta_{2}$, and $\vartheta_{4}$. It prevents self-fulfilling expectations with respect to the path of inflation. ${ }^{4}$ In order to satisfy the second requirement we disregard reaction functions which imply that the variance of the interest rate exceeds a threshold value. This threshold is set so that it is very unlikely that the interest rate hits the lower bound. ${ }^{5}$

\subsection{Equilibrium Dynamics}

In equilibrium all markets clear. Capital services employed in the production of primary goods equal

$$
K_{t}=K_{H t}+X_{t}, \quad X_{t}=\int_{0}^{1} X_{f t} d f
$$

and accumulate according to

$$
K_{t+1}-(1-\delta) K_{t}=\Psi\left(I_{t} / K_{t}\right) K_{t}
$$

\footnotetext{
${ }^{4}$ See, e.g., Bullard and Mitra (2002).

${ }^{5}$ See Appendix 3 for more details.
} 
Equation (2.21) implies

$$
q_{t} X_{t+1}=f\left(\bar{\omega}_{t}\right) g_{t} \tilde{Y}_{t}-\int_{0}^{1}\left(D_{f t}^{P}+\Delta_{f t}\right) d f
$$

where the right-hand side of Eq. (2.12) was used to replace $v_{t} M_{t}$. Aggregating Eq. (2.8) over all primary production firms yields

$$
N W_{t}=\left[q_{t}(1-\delta)+r_{Y t}+r_{K t}\right] X_{t}+\int_{0}^{1} \Delta_{f t} d f .
$$

Condition (2.19b) and Eq. (2.12) imply

$$
\tilde{Y}_{t}=\frac{v_{t}}{g_{t}} \frac{N W_{t}}{1-v_{t} h\left(\bar{\omega}_{t}\right)} .
$$

Consolidating the budget constraints of the household, the government, and the definition of dividend payments to the household yields

$$
g_{t} \tilde{Y}_{t}\left(\Omega_{t}-\Phi\left(\bar{\omega}_{t}\right) \kappa\right)+\int_{0}^{1}\left(\frac{P_{j t}}{P_{t}}-g_{t}\right) Y_{j t} d j=C_{t}+I_{t}+G_{t} .
$$

Market clearing for intermediary goods requires $\int_{0}^{1} Y_{j t} d j=\Omega_{t} \tilde{Y}_{t}$ and the first part of the integral term equals $Y_{t}$ (see (2.2)). Hence, the preceding equation reduces to the resource constraint:

$$
Y_{t}=C_{t}+I_{t}+G_{t}+\Phi\left(\bar{\omega}_{t}\right) \kappa g_{t} \tilde{Y}_{t}
$$

The last term on the right-hand-side reflects the resource costs of monitoring insolvent firms in the primary production sector.

We present the full system of equations that determine the dynamics of the model in the Appendix 1.

\subsection{Welfare Analysis}

Our goal is to determine whether or not the inclusion of Tobin's q in the Taylor rule (2.32) does improve monetary policy. Our point of reference is the welfare associated with the simple rule $\vartheta_{1}=\vartheta_{3}=\vartheta_{4}=0$ and $\vartheta_{2}=1.5$. In this case, the central bank reacts to the inflation gap only and ensures that the equilibrium path of the economy is determinate. Our choice of $\vartheta_{2}$ follows Taylor's (1993) seminal paper as well as Faia and Monacelli (2007). Let

$$
\begin{aligned}
& V_{t}:=V_{t}^{C}-V_{t}^{N}, \text { with } \\
& V_{t}^{C}:=\mathbb{E}_{t} \sum_{s=0}^{\infty} \beta^{s}\left[\frac{\left(C_{t+s}-\chi C_{t+s-1}\right)^{1-\eta}-1}{1-\eta}\right],
\end{aligned}
$$




$$
\begin{aligned}
V_{t}^{N} & :=\mathbb{E}_{t} \sum_{s=0}^{\infty} \beta^{s}\left[\frac{v_{0}}{1+v_{1}} \tilde{N}_{t+s}^{1+v_{1}}\right], \\
\tilde{N}_{t} & :=\left[\int_{0}^{1} N_{h t}^{1+v_{1}} d h\right]^{\frac{1}{1+v_{1}}} .
\end{aligned}
$$

denote the welfare associated with this solution and let

$$
\begin{aligned}
\bar{V}_{t} & =\bar{V}_{t}^{C}-\bar{V}_{t}^{N}, \text { with } \\
\bar{V}_{t}^{C} & :=\mathbb{E}_{t} \sum_{s=0}^{\infty} \beta^{s}\left[\frac{\left(\bar{C}_{t+s}-\chi \bar{C}_{t+s-1}\right)^{1-\eta}-1}{1-\eta}\right] \\
\bar{V}_{t}^{N} & :=\mathbb{E}_{t} \sum_{s=0}^{\infty} \beta^{s}\left[\frac{v_{0}}{1+v_{1}} \overline{\tilde{N}}_{t+s}^{1+v_{1}}\right] .
\end{aligned}
$$

denote the welfare obtained from a solution for a given quadruple $\left(\vartheta_{1}, \vartheta_{2}, \vartheta_{3}, \vartheta_{4}\right)$ from a given four-dimensional grid $\mathscr{D}$ with possibly non-zero values of $\vartheta_{1}, \vartheta_{3}$, and $\vartheta_{4}$. Accordingly, we implicitly define our measure of welfare enhancement $\lambda$ by $^{6}$

$$
\bar{V}_{t}=\mathbb{E}_{t} \sum_{s=0}^{\infty} \beta^{s}\left[\frac{\left((1-\lambda) C_{t+s}-\chi(1-\lambda) C_{t+s-1}\right)^{1-\eta}-1}{1-\eta}-\frac{v_{0}}{1+v_{1}} \tilde{N}_{t+s}^{1+v_{1}}\right] .
$$

Thus, $\lambda$ is the fraction by which consumption in the benchmark could be lowered $(\lambda>0)$ or has to be increased $(\lambda<0)$ to yield the same value of expected life-time utility as in the economy with the modified Taylor rule. Like the policy functions that solve the model, $\lambda$ is a function of the given initial state of the system. In our model the vector of state variables consists of the vector of shocks $\mathbf{z}_{t}=$ $\left[\ln Z_{t}, \ln \left(G_{t} / G\right)\right]^{\prime}$ and the endogenous states $\mathbf{x}_{t}$, which comprise the aggregate stock of capital $K_{t}$, the capital of primary producers $X_{t}$, the nominal interest rate factor $Q_{t}$, and, from the previous period, consumption $C_{t-1}$, the real wage $w_{t-1}$, the inflation factor $\pi_{t-1}$, the measure of price dispersion $s_{t-1}^{y}$, and the measure of wage dispersion $s_{t-1}^{n} \cdot{ }^{7}$ We approximate $\lambda\left(\mathbf{x}_{t}, \mathbf{z}_{t}\right)$ at the stationary point $(\mathbf{x}, \mathbf{y})$ of the deterministic counterpart of the model. In the Appendix 2, we show that by a second-order approximation

$$
\lambda \approx \frac{1-\beta}{1+(1-\eta)(1-\beta) V^{C}}\left[V_{\sigma \sigma}^{C}+\bar{V}_{\sigma \sigma}^{N}-\bar{V}_{\sigma \sigma}^{C}-V_{\sigma \sigma}^{N}\right]
$$

In this expression, $V_{\sigma \sigma}^{i}$ are the second partial derivatives of $V^{i}, i=C, N$, with

\footnotetext{
${ }^{6}$ Schmitt-Grohé and Uribe (2004a) do not compensate for consumption at time $t-1$. Their definition yields a smaller welfare measure since the household's utility is a decreasing function of the habit. However, because the ranking of different monetary policy rules is independent of the scale of the welfare measure, we use the analytically more convenient definition.

${ }^{7}$ See the Appendix 1, Eqs. (7.1e) and (7.2f) for the definition of these variables.
} 
respect to the scaling parameter $\sigma$ in the driving process of the shocks, $\mathbf{z}_{t}=\Pi \mathbf{z}_{t-1}+\sigma\left(\epsilon_{Z t}, \epsilon_{G t}\right)^{\prime}{ }^{8}$

\section{Calibration}

We calibrate the model with respect to the U.S. economy. The length of a period is one quarter. Table 1 summarizes the model's parameters and the values assigned to them. We thereby, for the most part, follow Christiano et al. (2005) and Carlstrom and Fuerst (1997). In particular, with respect to the credit friction we use a lognormal distribution of the idiosyncratic shock $\omega$, and determine the parameters of this distribution as well as the bankruptcy threshold $\bar{\omega}$ from three targets: a mean of one, a quarterly bankruptcy rate of 0.974 percent, and an annual external finance premium of 187 basis points. Given $\bar{\omega}$, Eq. (2.19a) determines the mark-up $v$, and the value of the additional discount factor $\gamma$ follows from the steady state versions of Eqs. (2.22) and (2.29b) as:

$$
\gamma=\frac{1-v g(\bar{\omega})}{v f(\bar{\omega})}
$$

The steady state share of government spending in output $G / Y=0.16$ as well as the parameters of the TFP shock and the government spending shock stem from Schmitt-Grohé and Uribe (2007). We also follow Schmitt-Grohé and Uribe (2005) and set the steady state inflation rate equal to the average growth rate of the U.S. GDP deflator over the period 1960-1998, which gives $\pi=1.042^{0.25}$.

Finally, to consider the potential of our model to produce a counter-cyclical external finance premium, we disregard the spillover from the aggregate shock to the mean of the distribution of the idiosyncratic productivity modeled in Faia and Monacelli (2007) and set $\Omega_{t}=1$ for all periods.

\section{Results}

In this section, we present our results on how the introduction of a q-target in the Taylor rule affects the utility of the households. In particular, we search for the optimal monetary policy rule and analyze if monetary policy should respond to higher asset prices by lowering or increasing interest rates. Our benchmark is the Taylor rule (2.32) with zero coefficients on the past interest rate $\vartheta_{1}=0$, a coefficient of $\vartheta_{2}=1.5$ on the inflation gap, and zero coefficients on capital price $\vartheta_{3}=0$ and the output gap $\vartheta_{4}=0$. We compute the welfare gains or losses of policies with $\left(\vartheta_{1}, \vartheta_{2}, \vartheta_{3}, \vartheta_{4}\right) \in \mathscr{D}$ over the grid

$$
\mathscr{D}:=\underbrace{[0,0.95]}_{\vartheta_{1}} \times \underbrace{[1.2,2.5]}_{\vartheta_{2}} \times \underbrace{[-2.5,2.5]}_{\vartheta_{2}} \times \underbrace{[0,2.5]}_{\vartheta_{4}} .
$$

\footnotetext{
${ }^{8}$ See Schmitt-Grohé and Uribe (2004b) for this representation.
} 
Table 1 Calibration of the model

\begin{tabular}{lll}
\hline Parameter & Value & Description \\
\hline$\beta$ & $1.03^{-0.25}$ & Subjective discount factor \\
$1 / \eta$ & 1 & Intertemporal elasticity of substitution \\
$1 / v_{1}$ & 1 & Frisch elasticity of labor supply \\
$\chi$ & 0.65 & Habit parameter \\
$N$ & 1 & Steady state labor supply \\
$\alpha$ & 0.36 & Share of capital in value added \\
$\delta$ & 0.025 & Rate of capital depreciation \\
$\zeta$ & $\{0.5,2.5\}$ & Elasticity of marginal adjustment cost function $\Psi^{\prime}$ \\
$\rho_{Z}$ & 0.856 & Autocorrelation of TFP shock \\
$\sigma_{Z}$ & 0.0064 & Standard deviation of innovations of TFP shock \\
$E(\omega)$ & 1 & Mean of distribution of idiosyncratic productivity shock \\
$\kappa$ & 0.25 & Costs of bankruptcy \\
$\Phi(\bar{\omega})$ & 0.00974 & Steady state bankruptcy rate \\
$1+r_{L}$ & $1.0187^{0.25}$ & Gross external finance premium \\
$\epsilon_{y}$ & 6 & Price elasticity of demand for intermediary goods \\
$\epsilon_{n}$ & 21 & Wage elasticity of labor demand \\
$\varphi_{y}$ & 0.60 & Fraction of intermediary goods firms not setting their prices optimally \\
$\varphi_{n}$ & 0.64 & Fraction of household members not setting their wages optimally \\
$G / Y$ & 0.16 & Share of government spending in steady state production \\
$\rho_{G}$ & 0.87 & Autocorrelation parameter in government spending shock \\
$\sigma_{G}$ & 0.016 & Standard deviation of innovations in government spending shock \\
$\pi$ & $1.042^{0.25}$ & Steady state inflation factor \\
\hline & & \\
\hline
\end{tabular}

for two different values of the parameter $\zeta$, indicating small and medium size costs of capital accumulation. Note that the grid points allow for zero values of the parameters $\vartheta_{1}, \vartheta_{3}$, and $\vartheta_{4}$, i.e., we do not exclude per se that all arguments of the Taylor rule (2.32) must indeed be present.

Table 2 presents the results obtained for the benchmark model without the financial friction. Apart from the monopoly power in product and labor markets, this model embeds three kinds of distortions: 1) The variable mark-up (the inverse of the variable $g_{t}$ ) over marginal costs and the variable mark-up over the marginal rate of substitution between leisure and consumption introduces inefficient fluctuations of hours and production. The combined effect of both distortions is reflected by the gap between the (aggregate) marginal product of labor (MPL) and the marginal rate of substitution between consumption and leisure (MRS) defined as

$$
\operatorname{gap}_{t}:=\frac{(1-\alpha) \tilde{Y}_{t} / N_{t}}{v_{0} N_{t}^{v_{1}} / \Lambda_{t}}
$$

Additionally, 2) the price and 3) wage dispersion forces the household members to spread consumption and labor supply unevenly over the continuum of consumption 
Table 2 Welfare effects: benchmark model without financial frictions

\begin{tabular}{llllll}
\hline & $\zeta=0.5$ & & & $\zeta=2.5$ \\
\cline { 2 - 3 } \cline { 5 - 6 } & $\mathrm{i}$ & ii & & iii & iv \\
\hline$\vartheta_{1}$ & 0.78 & 0.0 & 0.47 & 0.0 \\
$\vartheta_{2}$ & 2.38 & 2.5 & 1.20 & 2.5 \\
$\vartheta_{3}$ & -1.41 & 0.0 & & -0.46 & 0.0 \\
$\vartheta_{4}$ & 1.79 & 0.75 & & 0.75 & 0.75 \\
$\lambda$ & -0.0628 & -0.0451 & & -0.0341 & -0.0240 \\
\hline
\end{tabular}

$\zeta$ is the elasticity of Tobin's q with respect to the investment-capital ratio $I / K . \vartheta_{i}, i=1,2,3,4$ denote the coefficients of the Taylor rule (2.32) on the past interest rate, the inflation gap, the price of capital, and the output gap, respectively. $\lambda$ is the percentage of consumption that must be given (taken if positive) to the household in the pure inflation target regime with $\vartheta_{2}=1.5$ and $\vartheta_{i}=0, i=1,3,4$, to make him equally well-off as under the rule specified in columns $\mathrm{i}-\mathrm{iv}$

goods and labor services, respectively. ${ }^{9}$ However, as we show in Appendix 4, the percentage change of the measures of price and wage dispersion is close to zero so that the welfare implications should be negligible.

The Taylor rule that maximizes the welfare gain of the household in the case of small adjustment costs, $\zeta=0.5$, places a negative coefficient on the price of capital, $\vartheta_{3}=-1.41$. Compared to a policy which ignores this variable (columns $\mathrm{i}$ and ii), there is a welfare loss of about 0.018 percentage points. Also note that the optimal rule includes the output gap. Obviously, the different sources of distortions require information from several economic variables to fine tune the central bank's interest rate policy. In the case of high adjustment costs of capita, $\zeta=2.5$, the policy which includes Tobin's q implies a welfare increase of about 0.01 percentage points. This rule, too, includes the output gap.

The intuition behind this result rests on the observation that the cycle is mainly driven by the supply shock. Figures 2 and 3 display the response of the economy to a one-time shock in quarter $t=2$ for different specifications of the model. The Case 0 refers to the model without nominal rigidities and without the financial friction. Case 1 (Case 2) denotes the response of the model with the nominal frictions and the simple (optimal) Taylor rule, while Case 3 (Case 4) show the behavior of the model with nominal and financial frictions for the simple (optimal) Taylor rule.

A positive supply shock increases labor productivity. It is well-known that the increase in the real wage is not sufficient to offset the implicit labor tax implied by the adjustment costs of capital so that labor supply declines (see Panel 6 in Fig. 2). In economies with nominal frictions this effect is more pronounced since the real wage responds sluggishly. Accordingly, the gap between the MPL and the MRS widens (see Panel 5 in Fig. 3). If the central bank reduces its interest rate in response to the decreasing inflation the real rate of interest declines, since the nominal frictions prevent a full adjustment of expected inflation. The household increases

\footnotetext{
9 The latter two effects are not present in the model of Faia and Monacelli (2007), because they assume convex costs of price adjustment so that, in the symmetric equilibrium of the product market, all firms will choose the same price. In addition, they do not model wage stickiness.
} 

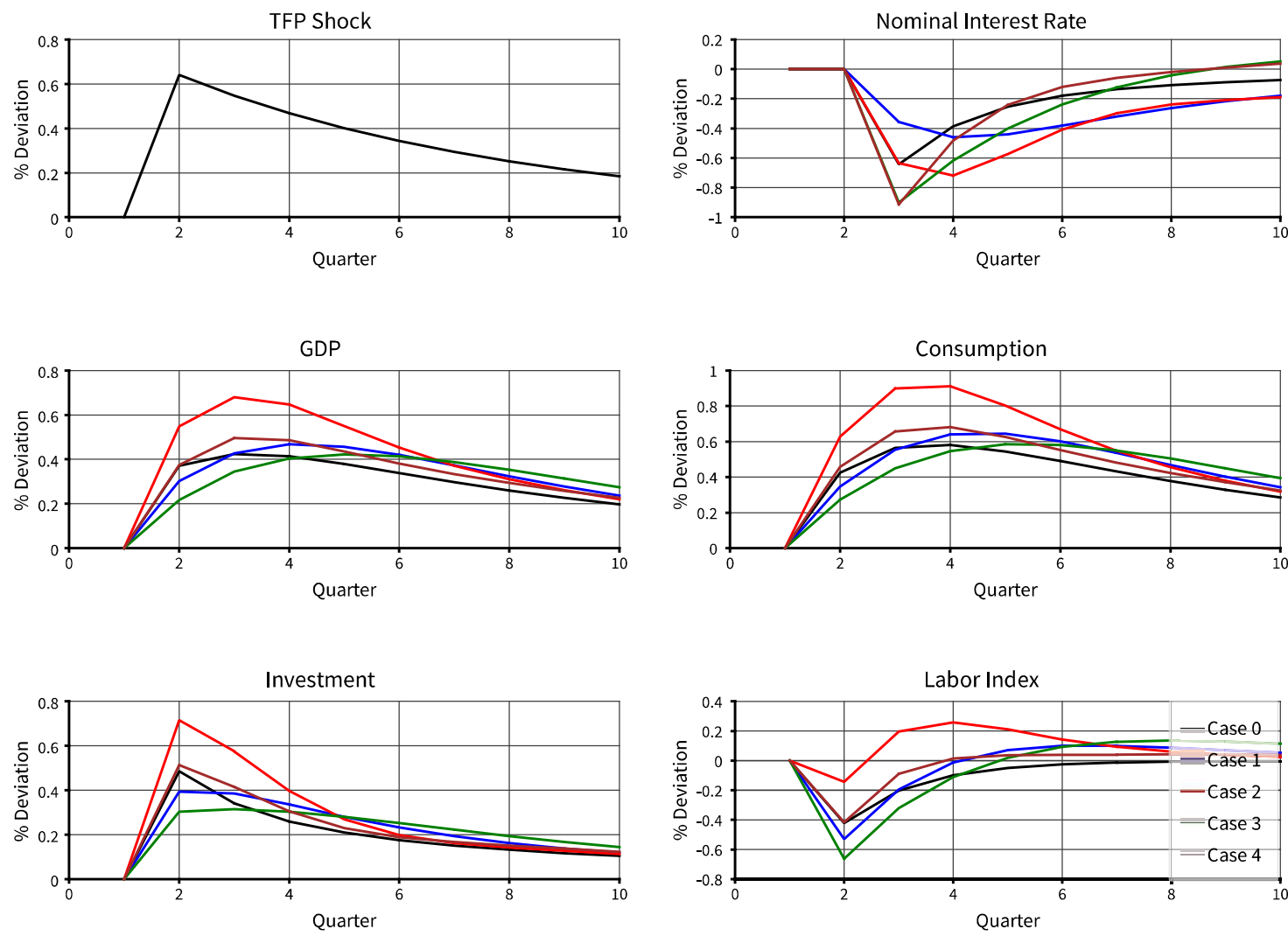

Fig. 2 Impulse responses part one. Notes: Case 0 refers to a model without nominal and financial frictions. Case 1 (2) refers to a model with nominal frictions only and the simple (optimal) Taylor rule. Case 3 (4) refers to the model with all frictions and the simple (optimal) Taylor rule

consumption and thus fuels the upswing. This effect is more pronounced if the central bank does not only react to inflation but also (inversely) to the increase in the price of capital. In this way, the monetary authority is able to temporarily lower the gap between the MPL and MRS and, accordingly, reduces the welfare distortions of price and wage setting. Fine tuning of the interest rate policy, thus, employs information from three different sources: inflation, the output gap, and the price of capital. Since the latter moves in the opposite direction as inflation, the welfare maximizing rule places a negative weight on the deviation of this variable from its stationary value.

In the model with financial frictions there is an interplay between adjustment costs of capital and the size of the financial friction. The technology shock boosts the demand for new capital and Tobin's q increases. In this way, the net wealth of producers increases and, therefore, reduces their demand for external funds. As a consequence, both the mark-up on factor costs and the external finance premium decline (see Panel 6 in Fig. 3). Our model is thus able to explain the observed counter-cyclicity of the external finance premium without the additional assumption in Faia and Monacelli (2007) of a spillover from aggregate technology shifts to the idiosyncratic shock. Eventually, this effect also introduces a channel between monetary policy and the financial friction: If the central bank stimulates the boom by lowering its interest rate it also indirectly reduces the financial friction. 

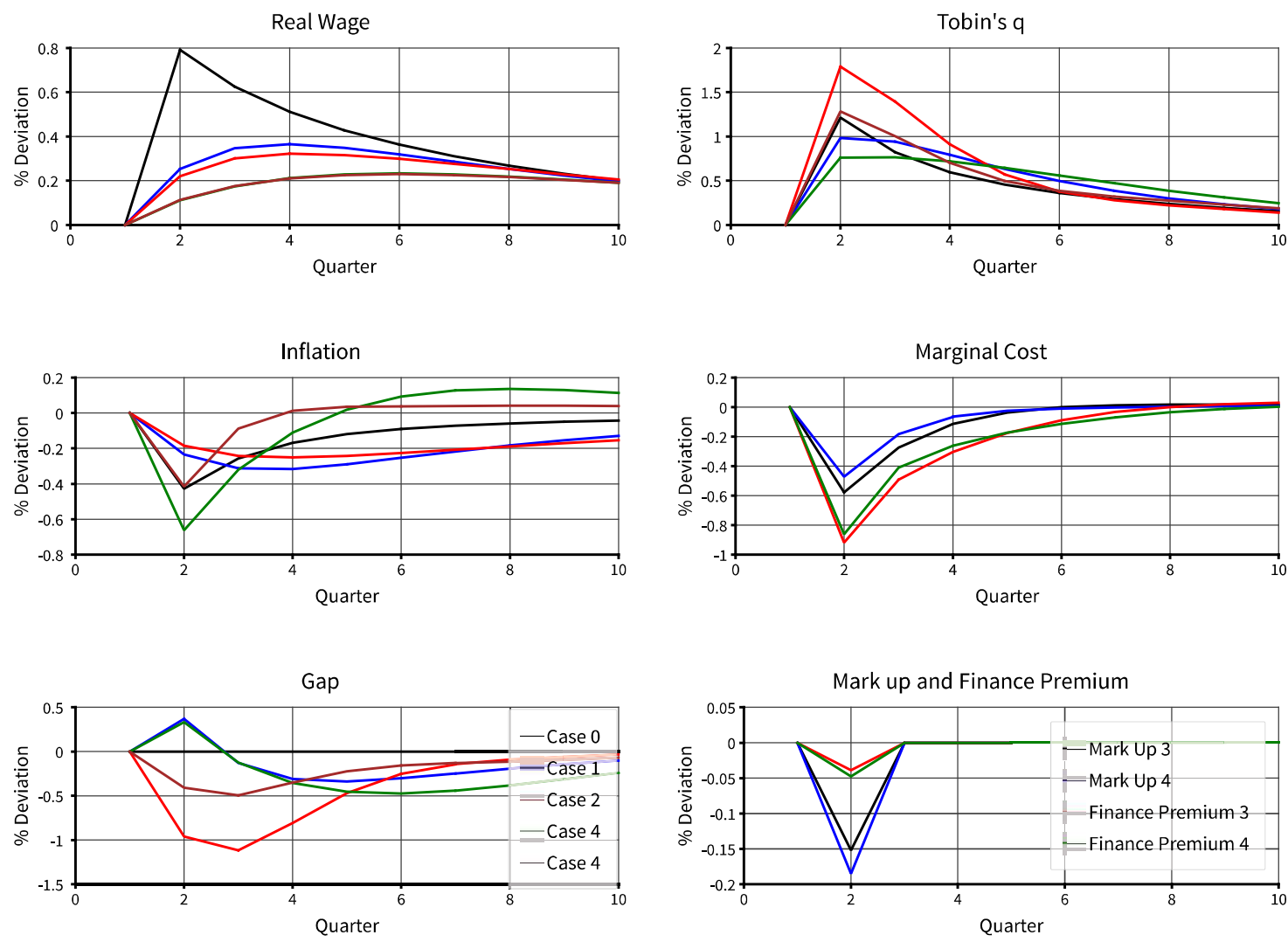

Fig. 3 Impulse responses part two. Notes: See Fig. 2

Table 3 Welfare effects: benchmark model with financial frictions

\begin{tabular}{lll}
\hline & $\zeta=0.5$ & $\zeta=2.5$ \\
\hline$\vartheta_{1}$ & 0.36 & 0.52 \\
$\vartheta_{2}$ & 1.79 & 1.22 \\
$\vartheta_{3}$ & -0.81 & -0.48 \\
$\vartheta_{4}$ & 0.97 & 0.82 \\
$\lambda$ & -0.0617 & -0.0355 \\
\hline
\end{tabular}

See Table 2

Table 3 presents the results for the benchmark model with the financial friction. ${ }^{10}$ The basic intuition behind the small welfare gain remains intact: it rests on the temporary alleviation of the welfare distortion of monopoly power from fueling the upswing triggered by the technology shock. In the case of $\zeta=2.5$ we also observe a small additional effect which stems from the inverse relation between the external finance premium and the relative price of capital. The fact that this effect is tiny is explained by the size of the potential welfare gain: to make the household in the financial friction economy equally well-off as in an economy without this friction

\footnotetext{
${ }^{10}$ Since the search for the optimal policy is relatively time-consuming in this model, we have not computed the welfare for policies that neglect the price of capital. The low speed of computation is caused by the repeated numerical evaluation of the Hessian matrix of the dynamic system of equations, some of which require numeric integration.
} 
would require an increase of consumption of less than one-hundredth of one percent $(\lambda \times 100=0.00975)$.

In the Appendix 4, we add a shock to the net wealth of primary goods producers. The effect of the shock on consumption, labor supply, and Tobin's q are similar to those of the TFP shock. The coincidence of a positive TFP shock and a negative wealth shock, thus, implies a smaller effect on the price of capital as in the benchmark model. Unsurprisingly, we find that the fine tuned Taylor in this model places (almost) zero weight on the price of capital.

\section{Robustness}

In this section, we examine the robustness of our main results with respect to the household's preference representation. On the one hand, we generalize our economy's welfare specification towards the Epstein and Zin (1989), henceforth EZ, utility recursion. On the other hand, we consider two additional demand shocks as we allow for exogenous shifts to the household's marginal rate of substitution (MRS) between consumption and leisure as well as to his discounting parameter. While such preference shocks have been demonstrated to be able to significantly improve on DSGE models' reconcilability with empirical macro-evidence, ${ }^{11}$ researchers have cast doubts on the theoretical soundness of such "dubiously structural" elements. ${ }^{12}$ The two considered preference shifts are, however, solidly founded in recent theoretical work. In particular, as shown by Nakajima (2005), the MRS shock can be interpreted as an aggregation of market incompleteness on the micro-level within a heterogenous agent economy, while Gourio (2012) demonstrates that the discounting shock is a reduced form of capturing the household's savings behavior in presence of a perceived (time-varying) positive probability of an economic disaster.

Formal Implementation The household's (centralized) value function is now required to (only) satisfy

$$
V_{t}=\left[(1-\beta) \mathscr{U}_{t}^{1-\frac{1}{\psi}}+\beta \vartheta_{t}\left(\mathbb{E}_{t}\left[V_{t+1}^{1-\eta}\right]\right)^{\frac{1-\frac{1}{\psi}}{1-\eta}}\right]^{\frac{1}{1-\frac{1}{\psi}}}, 1 \neq \psi>0 .
$$

Thereby, in order to still be able to apply the above outlined welfare analysis, the composite good is now of the Cobb-Douglas type, i.e.

$$
\mathscr{U}_{t}:=\left(C_{t}-\mathscr{C}_{t}\right)^{v}\left(1-N_{t}\right)^{\theta_{t}(1-v)}, v \in(0,1),
$$

and the preference shifts follow stationary $\mathrm{AR}(1)$ processes, i.e.

$$
\begin{aligned}
& \ln \vartheta_{t+1}=\rho_{\vartheta} \ln \vartheta_{t}+\sigma_{\vartheta} \epsilon_{t}^{\mathrm{BETA}}, \rho_{\vartheta} \in[0,1), \sigma_{\vartheta} \geq 0, \epsilon_{t}^{\mathrm{BETA}} \sim \operatorname{iid~N}(0,1), \\
& \ln \theta_{t+1}=\rho_{\theta} \ln \theta_{t}+\sigma_{\theta} \epsilon_{t}^{\mathrm{MRS}}, \rho_{\theta} \in[0,1), \sigma_{\theta} \geq 0, \epsilon_{t}^{\mathrm{MRS}} \sim \operatorname{iid~N}(0,1) .
\end{aligned}
$$

\footnotetext{
${ }^{11}$ See, e.g., Hall (1997).

12 See, e.g., Chari et al. (2009), p. 244.
} 
Note that $\psi$ directly measures the elasticity of intertemporal substitution (EIS) of the composite good and that $\eta$ independently parameterizes risk aversion (RA) such that attitudes towards risk and towards intertemporal substitution are disentangled. ${ }^{13}$

These changes directly affect the studied economy through two channels. First, its stochastic discount factor from period $t$ until $\tau$ now reads

$$
\Pi_{j=0}^{\tau}\left(\beta \vartheta_{t}\left(\frac{V_{t+j}}{\left(\mathbb{E}_{t+j-1}\left[V_{t+j}^{1-\eta}\right]\right)^{\frac{1}{1-\eta}}}\right)^{\frac{1}{\psi}-\eta}\right)\left(\frac{\mathscr{U}_{t+\tau}}{\mathscr{U}_{t}}\right)^{1-\frac{1}{\psi}} \frac{C_{t}-\mathscr{C}_{t}}{C_{t+\tau}-\mathscr{C}_{t+\tau}} .
$$

Second, the model's (optimal) wage equations necessarily also reflect the household's generalized objective.

Numerical Results We use the additional degree of freedom associated with the EZ representation to further confirm robustness with respect to the parametrization. In particular, we consider two different risk aversion scenarios, namely $\eta \in\{2,12\}$. In both cases, RA is parameterized at (roughly) 2: in the first case RA is measured with respect to the composite good, in the second case directly with respect to consumption. ${ }^{14}$ With regard to the intertemporal elasticity of substitution, we follow Gourio (2012) and choose $\psi=2$ (i.e. larger than unity) in order to keep the above outlined microfoundation behind the discounting shock intuitively intact. Note that we therefore implicitly assume the household to have a preference for earlier resolution of composite good uncertainty. With regard to the preference shift processes, we proceed as follows: First, we follow Basu and Bundick (2012) and fix $\rho_{\theta}=\rho_{\vartheta}=0.9$. Second, we calibrate the two remaining shock volatility parameters so that the model optimally replicates some stylized facts of the real U.S. economy such as the equity premium and business cycle statistics. In particular, we find $\sigma_{\vartheta}=0.0009$ and $\sigma_{\theta}=0.01$, where the small magnitude of the calibrated discount shock volatility mainly reflects the model's zero lower bound sensitivity with respect to this parameter.

Again applying the above outlined welfare approach, we find that the main conclusion from this preference generalization is that the central results are robust (see Table 4): While the central bank is advised to react negatively to its asset price target, the welfare effect of additionally considering such a target is negligible.

\section{Conclusion}

We have considered a model that merges adjustment costs of capital, a financial friction in the production of primary goods and Calvo-type frictions in the adjustment of nominal prices and wages. In this environment we have asked whether or not the central bank can increase the welfare of the representative

\footnotetext{
${ }^{13}$ Note, however, that the deviation from the reciprocity of EIS and RA within our basic framework of additively separable expected utility comes with the implicit assumption of non-indifference with respect to the timing of uncertainty resolution which is tricky to calibrate, cf. Epstein et al. (2014).

${ }^{14}$ Cf. Swanson (2012).
} 
Table 4 Welfare effects: EZ model with financial friction and preference shocks

\begin{tabular}{lll}
\hline & $\eta=2$ & $\eta=12$ \\
\hline$\vartheta_{1}$ & 0 & 0 \\
$\vartheta_{2}$ & 1.85 & 1.2 \\
$\vartheta_{3}$ & -0.13 & -0.13 \\
$\vartheta_{4}$ & 0.28 & 0 \\
$\lambda$ & -0.009 & -0.008 \\
\hline
\end{tabular}

Notes: See Table 2

household if - in addition to inflation and the output gap - it also links its interest rate to the price of new capital. Our answer to this question is: yes, but with negligible effects. The intuition behind this result rests on two observations: first, the financial friction imposes only a very small welfare loss. Second, the main way in which the central bank achieves welfare gains is not by reducing the financial friction but via the temporary reduction of the welfare distortions implied by monopoly power.

We regard these results as robust, since our analysis shows that they do not depend on the number and the source (demand or supply) of shocks that drive the business cycle. However, the (additional) presence of other types of financial frictions may still change the picture. E.g., as pointed out by Christiano et al. (2015), a shock to the economy's credit spread plays a major role in explaining the most recent great recession. We, therefore, plan to further extend our analysis with respect to a more general description that (simultaneously) allows for a number of different sources of financial frictions.

Acknowledgements This work is supported by the German Research Foundation (Deutsche Forschungsgemeinschaft) under grant MA 1110/3-1 within its priority program "Financial Market Imperfections and Macroeconomic Performance". We gratefully acknowledge this support.

\section{Appendix 1: Analysis of the Model}

\section{Price Setting}

Consider the relative price $P_{j t+s} / P_{t+s}$ of an intermediary goods producer $j$ receiving the signal to choose its optimal relative price $p_{A t}=P_{A t} / P_{t}$ in period $t$ and that has not been able to reset its price up to period $t+s$ :

$$
\frac{P_{j t+s}}{P_{t+s}}=\frac{\pi_{t+s-1} \cdots \pi_{t}}{\pi_{t+s} \cdots \pi_{t+1}} p_{A t}=\frac{\pi_{t}}{\pi_{t+s}} p_{A t} .
$$

Accordingly, the firm will choose $p_{A t}$ in period $t$ to maximize

$$
\mathbb{E}_{t} \sum_{s=0}^{\infty}\left(\beta \varphi_{y}\right)^{s} \frac{\Lambda_{t+s}}{\Lambda_{t}}\left[\left(\frac{\pi_{t}}{\pi_{t+s}} p_{A t}\right)^{-\epsilon_{y}} Y_{t+s}-g_{t+s}\left(\frac{\pi_{t}}{\pi_{t+s}} p_{A t}\right)^{1-\epsilon_{y}} Y_{t+s}\right] .
$$

The first-order condition for this problem is: 


$$
0=\mathbb{E}_{t} \sum_{s=0}^{\infty}\left(\beta \varphi_{y}\right)^{s} \frac{\Lambda_{t+s}}{\Lambda_{t}}\left[\left(1-\epsilon_{y}\right)\left(\frac{\pi_{t}}{\pi_{t+s}}\right)^{1-\epsilon_{y}} Y_{t+s} p_{A t}^{-\epsilon_{y}}+\epsilon_{y} g_{t+s}\left(\frac{\pi_{t}}{\pi_{t+s}}\right)^{-\epsilon_{y}} Y_{t+s} p_{A t}^{-\epsilon_{y}-1}\right]
$$

and can be written as

$$
\begin{aligned}
& p_{A t}=\frac{\epsilon_{y}}{\epsilon_{y}-1} \frac{\Gamma_{1 t}}{\pi_{t} \Gamma_{2 t}}, \\
& \Gamma_{1 t}=\mathbb{E}_{t} \sum_{s=0}^{\infty}\left(\beta \varphi_{y}\right)^{s} \pi_{t+s}^{\epsilon_{y}} g_{t+s} \Lambda_{t+s} Y_{t+s}=\pi_{t}^{\epsilon_{y}} g_{t} \Lambda_{t} Y_{t}+\left(\beta \varphi_{y}\right) \mathbb{E}_{t} \Gamma_{1 t+1}, \\
& \Gamma_{2 t}=\mathbb{E}_{t} \sum_{s=0}^{\infty}\left(\beta \varphi_{y}\right)^{s} \pi_{t+s}^{\epsilon_{y}-1} \Lambda_{t+s} Y_{t+s}=\pi_{t}^{\epsilon_{y}-1} \Lambda_{t} Y_{t}+\left(\beta \varphi_{y}\right) \mathbb{E}_{t} \Gamma_{2 t+1}
\end{aligned}
$$

The price index (2.3) implies

$$
P_{t}^{1-\epsilon_{y}}=\left(1-\varphi_{y}\right) P_{A t}^{1-\epsilon_{y}}+\varphi_{y} P_{N t}^{1-\epsilon_{y}}=\left(1-\varphi_{y}\right) P_{A t}^{1-\epsilon_{y}}+\varphi_{y}\left(\pi_{t-1} P_{t-1}\right)^{1-\epsilon_{y}} .
$$

The second equality follows from the updating rule (2.7) and the fact that the nonoptimizers are a random sample of optimizers and non-optimizers. Dividing by $P_{t}$ on both sides delivers:

$$
1=\left(1-\varphi_{y}\right) p_{A t}^{1-\epsilon_{y}}+\varphi_{y}\left(\pi_{t-1} / \pi_{t}\right)^{1-\epsilon_{y}} .
$$

Market clearing requires

$$
\tilde{Y}_{t}=\int_{0}^{1} Y_{j t} d j=\int_{0}^{1}\left(\frac{P_{j t}}{P_{t}}\right)^{-\epsilon_{y}} Y_{t} d j=\underbrace{\left(\frac{\tilde{P}_{t}}{P_{t}}\right)^{-\epsilon_{y}}}_{\equiv s_{t}^{y^{y}}} Y_{t}, \quad \tilde{P}_{t}^{-\epsilon_{y}} \equiv \int_{0}^{1} P_{j t}^{-\epsilon_{y}} d j,
$$

so that

$$
s_{t}^{y} Y_{t}=\tilde{Y}_{t}, \quad s_{t}^{y}:=\left(\int_{0}^{1} P_{j t}^{-\epsilon_{y}} d j\right) P_{t}^{\epsilon_{y}} .
$$

Using the same reasoning for $\tilde{P}_{t}$ as for the price index $P_{t}$ yields:

$$
s_{t}^{y}=\left(1-\varphi_{y}\right) p_{A t}^{-\epsilon_{y}}+\varphi_{y}\left(\pi_{t-1} / \pi_{t}\right)^{-\epsilon_{y}} s_{t-1}^{y} .
$$

\section{Wage Setting}

Consider the real wage $W_{h t} / P_{t}$ of a household member who has set his wage optimally in period $t$ to $\tilde{w}_{t}=W_{A t} / P_{t}$ and who has not been able to do so again until period $s=1,2, \ldots$. This is given by

$$
\frac{W_{N t+s}}{P_{t+s}}=\frac{\prod_{i=1}^{s} \pi_{t+i-1} W_{A t}}{\prod_{i=1}^{s} \pi_{t+s} P_{t}}=\frac{\pi_{t}}{\pi_{t+s}} \tilde{w}_{t},
$$


and the demand for his type of labor service equals

$$
N_{h t+s}=\left(\frac{\left(\pi_{t} / \pi_{t+s}\right) \tilde{w}_{t}}{w_{t+s}}\right)^{-\epsilon_{n}} N_{t+s}
$$

where $w_{t+s}$ denotes the real wage prevailing in period $t+s$. Accordingly, the Lagrangian for the optimal real wage reads:

$$
\begin{aligned}
\mathscr{L}= & \mathbb{E}_{t} \sum_{s=0}^{\infty}\left(\beta \varphi_{n}\right)^{s}\left\{\frac{\left(C_{h t+s}-\chi \bar{C}_{t+s}\right)^{1-\eta}-1}{1-\eta}-\frac{v_{0}}{1+v_{1}}\left[\left(\frac{\left(\pi_{t} / \pi_{t+s}\right) \tilde{w}_{t}}{w_{t+s}}\right)^{-\epsilon_{n}} N_{t+s}\right]^{1+v_{1}}\right. \\
& \left.+\Lambda_{h t+s}\left[\frac{\pi_{t}}{\pi_{t+s}} \tilde{w}_{t}\left(\frac{\left(\pi_{t} / \pi_{t+s}\right) \tilde{w}_{t}}{w_{t+s}}\right)^{-\epsilon_{n}} N_{t+s}+R M T\right]\right\} .
\end{aligned}
$$

The first-order condition with respect to $\tilde{w}_{t}$ is

$$
\begin{aligned}
0= & \mathbb{E}_{t} \sum_{s=0}^{\infty}\left(\beta \varphi_{n}\right)^{s}\left\{\epsilon_{n} v_{0} \tilde{w}_{t}^{-\epsilon_{n}\left(1+v_{1}\right)-1}\left(\frac{\left(\pi_{t} / \pi_{t+s}\right)}{w_{t+s}}\right)^{-\epsilon_{n}\left(1+v_{1}\right)} N_{t+s}^{1+v_{1}}\right. \\
& \left.+\left(1-\epsilon_{n}\right) \Lambda_{h t+s} \tilde{w}_{t}^{-\epsilon_{n}} w_{t+s}^{\epsilon_{n}}\left(\frac{\pi_{t}}{\pi_{t+s}}\right)^{1-\epsilon_{n}} N_{t+s}\right\}
\end{aligned}
$$

Using $\Lambda_{h t+s}=\Lambda_{t+s}$ this can be arranged to read

$$
\tilde{w}_{t}=\frac{\epsilon_{n}}{\epsilon_{n}-1} \frac{\Delta_{1 t}}{\Delta_{2 t}}
$$

where

$$
\begin{aligned}
\Delta_{1 t} & =v_{0} \mathbb{E}_{t} \sum_{s=0}^{\infty}\left(\beta \varphi_{n}\right)^{s}\left(\frac{\pi_{t} \tilde{w}_{t}}{\pi_{t+s} w_{t+s}}\right)^{-\epsilon_{n}\left(1+v_{1}\right)} N_{t+s}^{1+v_{1}} \\
= & v_{0}\left(\frac{\tilde{w}_{t}}{w_{t}}\right)^{-\epsilon_{n}\left(1+v_{1}\right)} N_{t}^{1+v_{1}}+\left(\beta \varphi_{n}\right) \mathbb{E}_{t}\left(\frac{\pi_{t} \tilde{w}_{t}}{\tilde{\pi}_{t+1} w_{t+1}}\right)^{-\epsilon_{n}\left(1+v_{1}\right)} \Delta_{1 t+1}, \\
\Delta_{2 t} & =\mathbb{E}_{t} \sum_{s=0}^{\infty}\left(\beta \varphi_{n}\right)^{s} \Lambda_{t+s}\left(\frac{\tilde{w}_{t}}{w_{t+s}}\right)^{-\epsilon_{n}}\left(\frac{\pi_{t}}{\pi_{t+s}}\right)^{1-\epsilon_{n}} N_{t+s}, \\
& =\Lambda_{t}\left(\frac{\tilde{w}_{t}}{w_{t}}\right)^{-\epsilon_{n}} N_{t}+\left(\beta \varphi_{n}\right) \mathbb{E}_{t}\left(\frac{\tilde{w}_{t}}{\tilde{w}_{t+1}}\right)^{-\epsilon_{n}}\left(\frac{\pi_{t}}{\pi_{t+1}}\right)^{1-\epsilon_{n}} \Delta_{2 t+1} .
\end{aligned}
$$

The wage index (2.25) implies

$$
W_{t}^{1-\epsilon_{n}}=\left(1-\varphi_{n}\right) W_{A t}^{1-\epsilon_{n}}+\varphi_{n}\left(\pi_{t-1} W_{t-1}\right)^{1-\epsilon_{n}}
$$

so that the real wage equals

$$
w_{t}^{1-\epsilon_{n}}=\left(1-\varphi_{n}\right) \tilde{w}_{t}^{1-\epsilon_{n}}+\varphi_{n}\left(\frac{\pi_{t-1}}{\pi_{t}} w_{t-1}\right)^{1-\epsilon_{n}}
$$


Finally consider the index

$$
\tilde{N}_{t}^{1+v_{1}}:=\int_{0}^{1} N_{h t}^{1+v_{1}} d h
$$

in the family's current-period utility function. Using (2.24), this can be written

$$
\tilde{N}_{t}^{1+v_{1}}=N_{t}^{1+v_{1}} \int_{0}^{1}\left(\frac{W_{h t}}{W_{t}}\right)^{-\epsilon_{n}\left(1+v_{1}\right)} d h
$$

Let

$$
\tilde{W}_{t}^{-\epsilon_{n}\left(1+v_{1}\right)}=\int_{0}^{1} W_{h t}^{-\epsilon_{n}\left(1+v_{1}\right)} d h=\left(1-\varphi_{n}\right)\left(W_{A t}\right)^{-\epsilon_{n}\left(1+v_{1}\right)}+\varphi_{n}\left(\pi_{t-1} W_{N t-1}\right)^{-\epsilon_{n}\left(1+v_{1}\right)}
$$

and

$$
\left(s_{t}^{n}\right)^{1+v_{1}}=\left(\frac{\tilde{W}_{t}}{W_{t}}\right)^{-\epsilon_{n}\left(1+v_{1}\right)}=\left(\frac{\tilde{W}_{t} / P_{t}}{W_{t} / P_{t}}\right)^{-\epsilon_{n}\left(1+v_{1}\right)}=\left(\frac{\tilde{w}_{t}}{w_{t}}\right)^{-\epsilon_{n}\left(1+v_{1}\right)} .
$$

Using the same line of argument employed to derive (7.1f) yields the dynamic equation for the measure of wage dispersion $s_{t}^{n}$ :

$$
\left(s_{t}^{n}\right)^{1+v_{1}}=\left(1-\varphi_{n}\right)\left(\frac{\tilde{w}_{t}}{w_{t}}\right)^{-\epsilon_{n}\left(1+v_{1}\right)}+\varphi_{n}\left(\frac{\pi_{t-1} w_{t-1}}{\pi_{t} w_{t}}\right)^{-\epsilon_{n}\left(1+v_{1}\right)}\left(s_{t-1}^{n}\right)^{1+v_{1}}
$$

so that

$$
\tilde{N}_{t}=s_{t}^{n} N_{t}, \quad s_{t}^{n}:=\left(\int_{0}^{1} W_{h t}^{-\epsilon_{n}\left(1+v_{1}\right)} d h\right)^{\frac{1}{1+v_{1}}} W_{t}^{-\epsilon_{n}} .
$$

Note that we must track the variable $\tilde{N}_{t}$ in order to compute our welfare measure.

\section{Dynamics}

The full model consists of Eqs. (7.1), (7.2), (2.5), (2.13), (2.19a), (2.20), (2.22), (2.29), (2.35), (2.36), (2.37), the resource constraint (2.38), the capital accumulation equation (2.34), the Taylor rule (2.32), and the dynamics of the shocks, (2.10) and (2.31), respectively. In order to compute our welfare measure we have to add the recursive definitions of $V_{t}^{C}$ and $V_{t}^{N}$ implied by (2.39). These are

$$
\begin{aligned}
V_{t}^{C} & =\left[\frac{\left(C_{t}-\chi C_{t-1}\right)^{1-\eta}-1}{1-\eta}\right]+\beta \mathbb{E}_{t} V_{t+1}^{C}, \\
V_{t}^{N} & =\frac{v_{0}}{1+v_{1}} \tilde{N}_{t}^{1+v_{1}}+\beta \mathbb{E}_{t} V_{t+1}^{N} .
\end{aligned}
$$

For convenience, we summarize the entire system below: 


$$
\begin{aligned}
& \Lambda_{t}=\left(C_{t}-\chi C_{t-1}\right)^{-\eta}, \\
& q_{t}=\frac{1}{\Psi^{\prime}\left(I_{t} / K_{t}\right)}, \\
& r_{K t}=q_{t} \Psi\left(I_{t} / K_{t}\right)-\left(I_{t} / K_{t}\right), \\
& w_{t}=(1-\alpha)\left(g_{t} / v_{t}\right) \tilde{Y}_{t} / N_{t}, \\
& r_{Y t}=\alpha\left(g_{t} / v_{t}\right) \tilde{Y}_{t} / K_{t}, \\
& \tilde{Y}_{t}=Z_{t} N_{t}^{1-\alpha} K_{t}^{\alpha}, \\
& 1=v_{t}\left[\Omega_{t}-\Phi\left(\bar{\omega}_{t}\right) \kappa-\frac{f\left(\bar{\omega}_{t}\right) \phi\left(\bar{\omega}_{t}\right) \kappa}{1-\Phi\left(\bar{\omega}_{t}\right)}\right], \\
& r_{L t}=\frac{\bar{\omega}_{t}}{h\left(\bar{\omega}_{t}\right)}-1, \\
& g_{t} \tilde{Y}_{t}=\frac{v_{t}}{1-v_{t} h\left(\bar{\omega}_{t}\right)}\left[q_{t}(1-\delta)+r_{Y t}+r_{K t}\right] X_{t}, \\
& p_{A t}=\frac{\epsilon_{y}}{\epsilon_{y}-1} \frac{\Gamma_{1 t}}{\pi_{t} \Gamma_{2 t}}, \\
& 1=\left(1-\varphi_{y}\right) p_{A t}^{1-\epsilon_{y}}+\varphi_{y}\left(\pi_{t-1} / \pi_{t}\right)^{1-\epsilon_{y}}, \\
& s_{t}^{y}=\left(1-\varphi_{y}\right) p_{A t}^{-\epsilon_{y}}+\varphi_{y}\left(\pi_{t-1} / \pi_{t}\right)^{-\epsilon_{y}} s_{t-1}^{y}, \\
& s_{t}^{y} Y_{t}=\tilde{Y}_{t}, \\
& \tilde{w}_{t}=\frac{\epsilon_{n}}{\epsilon_{n}-1} \frac{\Delta_{1 t}}{\Delta_{2 t}}, \\
& w_{t}^{1-\epsilon_{n}}=\left(1-\varphi_{n}\right) \tilde{w}_{t}^{1-\epsilon_{n}}+\varphi_{n}\left(\frac{\pi_{t-1}}{\pi_{t}} w_{t-1}\right)^{1-\epsilon_{n}} \text {, } \\
& \left(s_{t}^{n}\right)^{1+v_{1}}=\left(1-\varphi_{n}\right)\left(\frac{\tilde{w}_{t}}{w_{t}}\right)^{-\epsilon_{n}\left(1+v_{1}\right)}+\varphi_{n}\left(\frac{\pi_{t-1} w_{t-1}}{\pi_{t} w_{t}}\right)^{-\epsilon_{n}\left(1+v_{1}\right)}\left(s_{t-1}^{n}\right)^{1+v_{1}}, \\
& \tilde{N}_{t}=s_{t}^{n} N_{t}, \\
& Y_{t}=C_{t}+I_{t}+G_{t}+\Phi\left(\bar{\omega}_{t}\right) \kappa g_{t} \tilde{Y}_{t}, \\
& K_{t+1}=\Psi\left(I_{t} / K_{t}\right) K_{t}+(1-\delta) K_{t},
\end{aligned}
$$




$$
\begin{aligned}
& q_{t} X_{t+1}=f\left(\bar{\omega}_{t}\right) g_{t} \tilde{Y}_{t}-D_{t}^{P}-\Delta_{t}^{P} \\
& Q_{t+1}=Q_{t}^{\delta_{1}}\left(\frac{\pi}{\beta}\right)^{1-\delta_{1}}\left(\frac{\pi_{t}}{\pi}\right)^{\delta_{2}}\left(q_{t}\right)^{\delta_{3}}\left(Y_{t} / Y\right)^{\delta_{4}} \\
& q_{t}=\beta \mathbb{E}_{t} \frac{\Lambda_{t+1}}{\Lambda_{t}}\left(q_{t+1}(1-\delta)+r_{Y t+1}+r_{K t+1}\right), \\
& 1=\beta \mathbb{E}_{t} \frac{\Lambda_{t+1}}{\Lambda_{t}} \frac{Q_{t+1}}{\pi_{t+1}} \\
& q_{t}=\gamma \beta \mathbb{E}_{t} \frac{\Lambda_{t+1}}{\Lambda_{t}}\left[q_{t+1}(1-\delta)+r_{Y t+1}+r_{K t+1}\right] \frac{v_{t+1} f\left(\bar{\omega}_{t+1}\right)}{1-v_{t+1} h\left(\bar{\omega}_{t+1}\right)}, \\
& \Gamma_{1 t}=\mathbb{E}_{t} \sum_{s=0}^{\infty}\left(\beta \varphi_{y}\right)^{s} \pi_{t+s}^{\epsilon_{y}} g_{t+s} \Lambda_{t+s} Y_{t+s}=\pi_{t}^{\epsilon_{y}} g_{t} \Lambda_{t} Y_{t}+\left(\beta \varphi_{y}\right) \mathbb{E}_{t} \Gamma_{1 t+1}, \\
& \Gamma_{2 t}=\mathbb{E}_{t} \sum_{s=0}^{\infty}\left(\beta \varphi_{y}\right)^{s} \pi_{t+s}^{\epsilon_{y}-1} \Lambda_{t+s} Y_{t+s}=\pi_{t}^{\epsilon_{y}-1} \Lambda_{t} Y_{t}+\left(\beta \varphi_{y}\right) \mathbb{E}_{t} \Gamma_{2 t+1}, \\
& \Delta_{1 t}=v_{0}\left(\frac{\tilde{w}_{t}}{w_{t}}\right)^{-\epsilon_{n}\left(1+v_{1}\right)} N_{t}^{1+v_{1}}+\left(\beta \varphi_{n}\right) \mathbb{E}_{t}\left(\frac{\pi_{t} \tilde{w}_{t}}{\tilde{\pi}_{t+1} w_{t+1}}\right)^{-\epsilon_{n}\left(1+v_{1}\right)} \Delta_{1 t+1} \\
& \Delta_{2 t}=\Lambda_{t}\left(\frac{\tilde{w}_{t}}{w_{t}}\right)^{-\epsilon_{n}} N_{t}+\left(\beta \varphi_{n}\right) \mathbb{E}_{t}\left(\frac{\tilde{w}_{t}}{\tilde{w}_{t+1}}\right)^{-\epsilon_{n}}\left(\frac{\pi_{t}}{\pi_{t+1}}\right)^{1-\epsilon_{n}} \Delta_{2 t+1}, \\
& V_{t}^{C}=\left[\frac{\left(C_{t}-\chi C_{t-1}\right)^{1-\eta}-1}{1-\eta}\right]+\beta \mathbb{E}_{t} V_{t+1}^{C}, \\
& V_{t}^{N}=\frac{v_{0}}{1+v_{1}} \tilde{N}_{t}^{1+v_{1}}+\beta \mathbb{E}_{t} V_{t+1}^{N} .
\end{aligned}
$$

\section{Stationary Solution and Calibration}

The model is solved via a second-order approximation of the decision rules at the stationary solution of the deterministic version of the model. This solution follows from the model's equations if we set the shocks equal to $Z_{t}=1$, and $G_{t}=G$ and cancel the time indices.

In the first step we determine $v$ and $\bar{\omega}$. We proceed as Carlstrom and Fuerst $(1997,1998)$ and employ a log-normal distribution for $\phi$ with parameters $\mu_{\omega}$ and $\sigma_{\omega}$. We determine these parameters and the stationary bankruptcy threshold $\bar{\omega}$ from three conditions:

i. We assume a mean of one: $\mathbb{E}(\omega)=\Omega=1$, 
ii. a bankruptcy rate of $\Phi(\bar{\omega})=0.00974$ (taken from Carlstrom and Fuerst (1998), p. 590).

iii. and an external finance premium of $\frac{\bar{\omega}}{h(\bar{\omega})}-1=r_{L}=1.0187^{0.25}-1$ (also taken from Carlstrom and Fuerst (1998), p. 590)

Given $\bar{\omega}$ we can solve (7.4.7) for $v$.

In the second step we determine the additional discount parameter $\gamma$. The stationary versions of (7.4.22) and (7.4.24) imply

$$
\gamma=\frac{1-v g(\bar{\omega})}{v f(\bar{\omega})} .
$$

In the third step we solve the stationary wage and price equations. It is immediate from Eq. (7.4.11) that $p_{A}=1$ so that Eq. (7.4.12) implies $s^{y}=1$ and Eq. (7.4.13) $Y=\tilde{Y}$. Equations (7.4.10), (7.4.25), and (7.4.26) deliver

$$
\begin{gathered}
g=\frac{\epsilon_{y}-1}{\epsilon_{y}}, \\
\Gamma_{1}=\frac{g \Lambda Y \pi^{\epsilon}}{1-\beta \varphi_{y}}, \\
\Gamma_{2}=\frac{\Lambda Y \pi^{\epsilon-1}}{1-\beta \varphi_{y}} .
\end{gathered}
$$

Equation (7.4.15) implies $\tilde{w}=w$ so that $\tilde{s}^{n}=1$ via (7.4.16) and $N=\tilde{N}$ from (7.4.17). The stationary values of the auxiliary variables follow from (7.4.27) and $(7.4 .28)$ as

$$
\begin{aligned}
& \Delta_{1}=v_{0} \frac{N^{1+v_{1}}}{1-\beta \varphi_{n}}, \\
& \Delta_{2}=\frac{\Lambda N}{1-\beta \varphi_{n}}
\end{aligned}
$$

so (7.4.14) implies

$$
v_{0} N^{v_{1}}=\frac{\epsilon_{n}-1}{\epsilon_{n}} \Lambda w
$$

In the fourth step we solve for $Y$ / $K$. Our assumption with respect to the function $\Psi$ in (2.34) imply $q=1$ (see (2.5a)) and $r_{K}=0$ (see (2.5b)) so that Eqs. (7.4.5) and (7.4.22) can be solved for

$$
\frac{Y}{K}=\frac{1-\beta(1-\delta)}{\alpha \beta(g / v)} .
$$

The production function (7.4.6) yields 


$$
\frac{K}{N}=\left(\frac{Y}{K}\right)^{\frac{1}{\alpha-1}}
$$

Given $N$ this allows us to compute $K, Y, I=\delta K$. The solution for consumption follows from (7.4.18):

$$
C=Y(1-g \Phi(\bar{\omega}) \kappa)-I-G
$$

so that $\Lambda$ is determined by $(7.4 .1)$ :

$$
\Lambda=[(1-\chi) C]^{-\eta}
$$

Equation (7.4.4) determines the stationary real wage $w$. We are now able to determine the parameter $v_{0}$ from condition (7.5f) and the auxiliary variables $\Gamma_{1}, \Gamma_{2}$, $\Delta_{1}$ and $\Delta_{2}$ from $(7.5 b)-(7.5 e)$.

In the last step we can compute the stock of capital owned by firms in the primary sector from (7.4.9)

$$
X=\frac{g Y(1-v g(\bar{\omega}))}{v\left(1-\delta+r_{Y}\right)}
$$

and dividends distributed from primary production firms to the household from (2.35)

$$
D^{P}=f(\bar{\omega}) g \tilde{Y}-X-\Delta^{P}
$$

In our simulations we follow Carlstrom and Fuerst (1998) and set $\Delta^{P}=0 .{ }^{15}$ The stationary values of the life-time utility associated with consumption $V^{C}$ and working hours $V^{N}$ equal

$$
\begin{aligned}
V^{C} & =\frac{1}{1-\beta} \frac{[(1-\chi) C]^{1-\eta}-1}{1-\eta}, \\
V^{N} & =\frac{1}{1-\beta} \frac{v_{0}}{1+v_{1}} N^{1+v_{1}} .
\end{aligned}
$$

Finally, the stationary version of the Euler equation (7.4.23) determines the nominal interest rate

$$
Q=\frac{\pi}{\beta}
$$

\section{Appendix 2: Approximation of $\lambda$}

Note that

15 Carlstrom and Fuerst (1997) assume that $\Delta_{t}^{P}$ equals the wage income of entrepreneurs $\alpha_{e} \tilde{Y}_{t}$ with $\alpha_{e}$ close to zero and ignore this term in their 1998 paper. 


$$
(1-\lambda)^{1-\eta} V_{t}^{C}+\frac{(1-\lambda)^{1-\eta}-1}{(1-\eta)(1-\beta)}=\mathbb{E}_{t} \sum_{s=0}^{\infty} \beta^{s} \frac{(1-\lambda)^{1-\eta}\left(C_{t+s}-\chi C_{t+s-1}\right)^{1-\eta}-1}{1-\eta}
$$

so that condition $(2.41)$ can be written

$$
\bar{V}_{t}=\bar{V}_{t}^{C}-\bar{V}_{t}^{N}=(1-\lambda)^{1-\eta} V_{t}^{C}+\frac{(1-\lambda)^{1-\eta}-1}{(1-\eta)(1-\beta)}-V_{t}^{N} .
$$

This equation can be solve for $\lambda$, yielding

$$
\lambda=1-\left[\frac{1+(1-\eta)(1-\beta)\left[\bar{V}_{t}^{C}+V_{t}^{N}-\bar{V}_{t}^{N}\right]}{1+(1-\eta)(1-\beta) V_{t}^{C}}\right]^{\frac{1}{1-\eta}}
$$

Thus, with $\sigma=1$, we get

$$
\lambda \simeq \lambda(\mathbf{x})+\lambda_{\sigma}(\mathbf{x})+\frac{1}{2} \lambda_{\sigma \sigma}
$$

With identical initial conditions $\lambda(\mathbf{x})=0$. As shown by Schmitt-Grohé and Uribe (2004a), the first-order effect of the scaling factor $\sigma$ on the policy functions of the model is nil. As a consequence, $\lambda_{\sigma}(\mathbf{x})=0$. Using this and differentiating (8.1) twice yields the Eq. (2.42) in the body of the paper.

\section{Appendix 3: Zero Lower Bound}

The Taylor rules which we consider must satisfy the non-negativity constraint on the nominal interest rate: $Q_{t} \geq 1$. Since our solution rests on perturbation methods, we cannot directly take care of this constraint. We, thus, follow Schmitt-Grohé and Uribe (2004a), p.31, who propose to disregard solutions which entail a significant probability to violate this constraint. Assume $Q_{t}-Q$ is distributed normally with mean zero and variance $\sigma_{Q}$ so that $\bar{z} \equiv\left(Q_{t}-Q\right) / \sigma_{Q}$ is a standard normal random variable. For $\bar{z}=-2.05$ the probability of the event $z \leq \bar{z}$ is 2 percent. Therefore, we disregard solutions for which $\sigma_{Q} \geq(Q-1) / 2.05$.

To determine whether or not a particular monetary policy violates this condition, we must compute the unconditional variance $\sigma_{Q}^{2}$ of the deviation of the interest factor $Q_{t}$ from its non-stochastic stationary solution $Q$.

Let

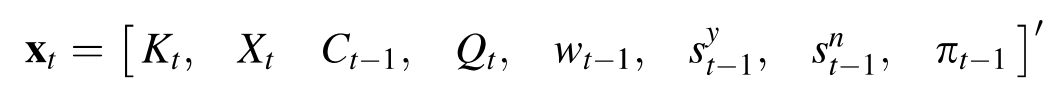

denote the vector of endogenous state variables, $\overline{\mathbf{x}}_{t}=\mathbf{x}_{t}-\mathbf{x}$ the deviation of the states from the non-stochastic steady state, and $\mathbf{z}_{t}=\left[\ln Z_{t}, \ln \left(G_{t} / G\right)\right]^{\prime}$ the vector of exogenous state variables. The first-order solution of the model is given by

$$
\begin{aligned}
& \overline{\mathbf{x}}_{t+1}=L^{x} \overline{\mathbf{x}}_{t}+L^{z} \mathbf{z}_{t}, \\
& \mathbf{z}_{t+1}=\Pi \mathbf{z}_{t}+\epsilon_{t+1}, \quad \mathbb{E}\left(\boldsymbol{\epsilon}_{t+1} \epsilon_{t+1}^{\prime}\right)=\Sigma^{\epsilon}=\Omega \Omega^{\prime} .
\end{aligned}
$$


We seek to determine $\Sigma^{x} \equiv \mathbb{E}\left(\overline{\mathbf{x}}_{t} \overline{\mathbf{x}}_{t}^{\prime}\right)$. Since $\mathbf{z}_{t}$ is a stationary stochastic process and since the eigenvalues of $L^{x}$ are within the unit circle, $\Sigma^{x}$ exists and is independent of the time index $t$. Multiplying both sides of (9.1) with $\overline{\mathbf{x}}_{t+1}$ yields:

$$
\begin{aligned}
\mathbb{E}\left(\overline{\mathbf{x}}_{t+1} \overline{\mathbf{x}}_{t+1}^{\prime}\right) & =\mathbb{E}\left(L^{x} \overline{\mathbf{x}}_{t}+L^{z} \mathbf{z}_{t}\right)\left(L^{x} \overline{\mathbf{x}}_{t}+L^{z} \mathbf{z}_{t}\right)^{\prime} \\
& =\mathbb{E}\left(L^{x} \overline{\mathbf{x}}_{t} \overline{\mathbf{x}}_{t}^{\prime}\left(L^{x}\right)^{\prime}\right)+\mathbb{E}\left(L^{z} \mathbf{z}_{t} \mathbf{z}_{t}^{\prime}\left(L^{z}\right)^{\prime}\right)+\mathbb{E}\left(L^{x} \overline{\mathbf{x}}_{t} \mathbf{z}_{t}^{\prime}\left(L^{z}\right)^{\prime}\right)+\mathbb{E}\left(L^{z} \mathbf{z}_{t} \overline{\mathbf{x}}_{t}^{\prime}\left(L^{x}\right)^{\prime}\right), \\
\Sigma^{x} & =L^{x} \Sigma^{x}\left(L^{x}\right)^{\prime}+L^{z} \Sigma^{z}\left(L^{z}\right)^{\prime}+L^{x} \Sigma^{x z}\left(L^{z}\right)^{\prime}+L^{z}\left(\Sigma^{x z}\right)^{\prime}\left(L^{x}\right)^{\prime} .
\end{aligned}
$$

Applying the vec-operator on both sides of the previous equation yields: ${ }^{16}$

$$
\operatorname{vec} \Sigma^{x}=\left(I_{n(x)^{2}}-L^{x} \otimes L^{x}\right)^{-1} \operatorname{vec}\left(L^{z} \Sigma^{z}\left(L^{z}\right)^{\prime}+L^{x} \Sigma^{x z}\left(L^{z}\right)^{\prime}+L^{z}\left(\Sigma^{x z}\right)^{\prime}\left(L^{x}\right)^{\prime}\right) .
$$

The matrices $\Sigma^{x z}$ and $\Sigma^{z}$ in this expression follow from the same reasoning. Consider $\Sigma^{x z}=\mathbb{E}\left(\overline{\mathbf{x}}_{t} \mathbf{z}_{t}^{\prime}\right)$ :

$$
\begin{aligned}
\Sigma^{x z} & =\mathbb{E}\left(\overline{\mathbf{x}}_{t+1} \mathbf{z}_{t+1}^{\prime}\right)=\mathbb{E}\left(L^{x} \overline{\mathbf{x}}_{t}+L^{z} \mathbf{z}_{t}\right)\left(\Pi \mathbf{z}_{t}+\boldsymbol{\epsilon}_{t+1}\right)^{\prime}, \\
& =\mathbb{E}\left(L^{x} \overline{\mathbf{x}}_{t} \mathbf{z}_{t}^{\prime} \Pi^{\prime}\right)+\mathbb{E}\left(L^{z} \mathbf{z}_{t} \mathbf{z}_{t}^{\prime} \Pi^{\prime}\right)+\mathbb{E}\left(L^{x} \overline{\mathbf{x}}_{t} \epsilon_{t+1}^{\prime}\right)+\mathbb{E}\left(L^{z} \mathbf{z}_{t} \epsilon_{t+1}^{\prime}\right), \\
\Sigma^{x z} & =L^{x} \Sigma^{x z} \Pi^{\prime}+L^{z} \Sigma^{z} \Pi^{\prime},
\end{aligned}
$$

because the expectation of the terms that involve $\epsilon_{t+1}$ is zero, since $\mathbf{z}_{t}$ and $\overline{\mathbf{x}}_{t}$ are predetermined when $\epsilon_{t+1}$ is realized. Therefore,

$$
\operatorname{vec} \Sigma^{x z}=\left(I_{n(x) n(z)}-\Pi \otimes L^{x}\right)^{-1} \operatorname{vec}\left(L^{z} \Sigma^{z} \Pi^{\prime}\right) .
$$

Finally:

$$
\begin{aligned}
\Sigma^{z} & \equiv \mathbb{E}\left(\mathbf{z}_{t+1} \mathbf{z}_{t+1}^{\prime}\right)=\mathbb{E}\left(\Pi \mathbf{z}_{t}+\boldsymbol{\epsilon}_{t+1}\right)\left(\Pi \mathbf{z}_{t}+\boldsymbol{\epsilon}_{t+1}\right)^{\prime} \\
& =\mathbb{E}\left(\Pi \mathbf{z}_{t} \mathbf{z}_{t}^{\prime} \Pi^{\prime}\right)+\mathbb{E}\left(\boldsymbol{\epsilon}_{t+1} \boldsymbol{\epsilon}_{t+1}^{\prime}\right)+\mathbb{E}\left(\Pi \mathbf{z}_{t} \boldsymbol{\epsilon}_{t+1}^{\prime}\right)+\mathbb{E}\left(\boldsymbol{\epsilon}_{t+1} \mathbf{z}_{t}^{\prime} \Pi^{\prime}\right), \\
\Sigma^{z} & =\Pi \Sigma^{z} \Pi^{\prime}+\Sigma^{\epsilon}
\end{aligned}
$$

so that

$$
\operatorname{vec} \Sigma^{z}=\left(I_{n(z)^{2}}-\Pi \otimes \Pi\right)^{-1} \operatorname{vec} \Sigma^{\epsilon}
$$

Equations (9.3) allow us to compute $\sigma_{Q}$ as the square root of the third diagonal element of $\Sigma^{x}$, given the model's first order solution $L^{x}$ and $L^{z}$.

\footnotetext{
16 The respective rule is $\operatorname{vec}(A B C)=\left(C^{\prime} \otimes A\right) \operatorname{vec} B$, where $\otimes$ denotes the Kronecker product of the matrices $C^{\prime}$ and $A$. Since the eigenvalues of $C^{\prime} \otimes A$ are equal to the product of the eigenvalues of $C^{\prime}$ and $A$, the eigenvalues of $L^{x} \otimes L^{x}$ are within the unit circle and $I-L^{x} \otimes L^{x}$ is invertible. See Lütkepohl (2005), p. 661-662 for these results.
} 


\section{Appendix 4: Additional Results}

\section{Impulse Response of Price and Wage Dispersion}

Figure 4 presents the impulse response of the measures of price and wage dispersion, $s_{t}^{y}$ and $s_{t}^{n}$, respectively, to a shock to total factor productivity. The scale on the ordinate are percentage points. Both measures have a steady state value of unity, in which case all price setters set the same price and all wage setters demand the same wage. The shock lowers the marginal costs of production so that firms being able to reset their price decrease prices. Equation (7.4.12), thus, implies that the measure of price dispersion will increase. On the contrary, the measure of wage dispersion decreases, since the wage setters demand higher wages (see Eq. (7.4.16)). However, the size of the change of both measures is almost negligible.

\section{Wealth Shock}

As an additional exercise to study the sensitivity of our results we add a third shock to our benchmark model. As Mimir (2016), we assume that a financial shock proportionately changes the net wealth of all producers in the primary sector, i.e., we change Eq. (7.4.9) to

$$
g_{t} \tilde{Y}_{t}=\frac{v_{t}}{1-v_{t} h\left(\bar{\omega}_{t}\right)}\left[q_{t}(1-\delta)+r_{Y t}+r_{K t}\right] X_{t} e^{\xi_{t}},
$$

and assume that $\xi_{t}$ follows a first-order autoregressive process
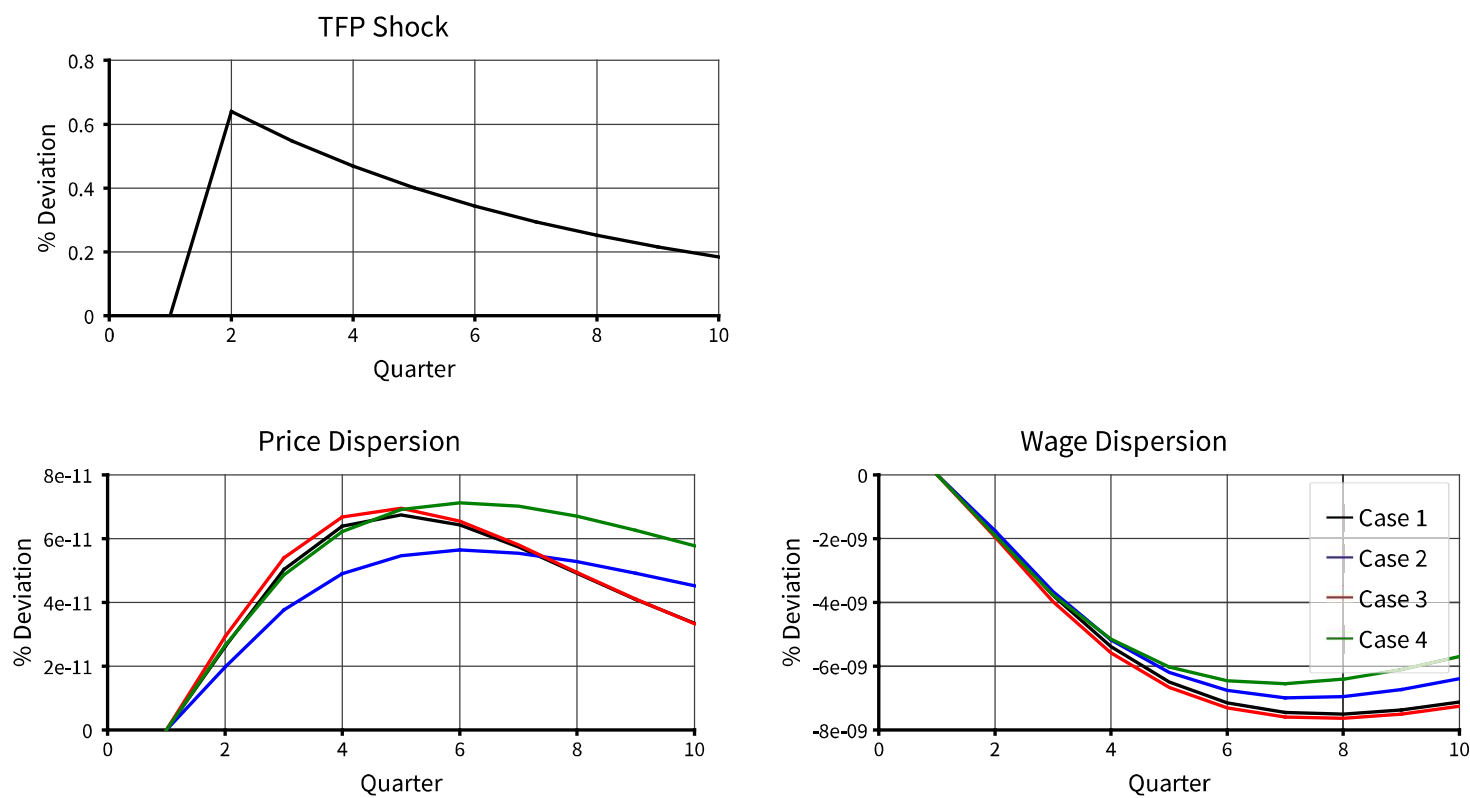

Fig. 4 Impulse responses of price and wage dispersion. Notes: Case 1 (2) refers to a model with nominal frictions only and the simple (optimal) Taylor rule. Case 3 (4) refers to the model with all frictions and the simple (optimal) Taylor rule 


$$
\xi_{t}=\rho_{\xi} \xi_{t-1}+\epsilon_{\xi t}, \quad \epsilon_{\xi t} \quad \text { iid } \quad \mathrm{N}\left(0, \sigma_{\xi}^{2}\right) .
$$

We take the values of the parameters $\rho_{\xi}=0.37$ and $\sigma_{\xi}=0.05$ from the estimates of Mimir (2016).

A positive wealth shock decreases the external finance premium and lowers the mark-up on factor costs. Therefore, intermediary goods prices decrease and real
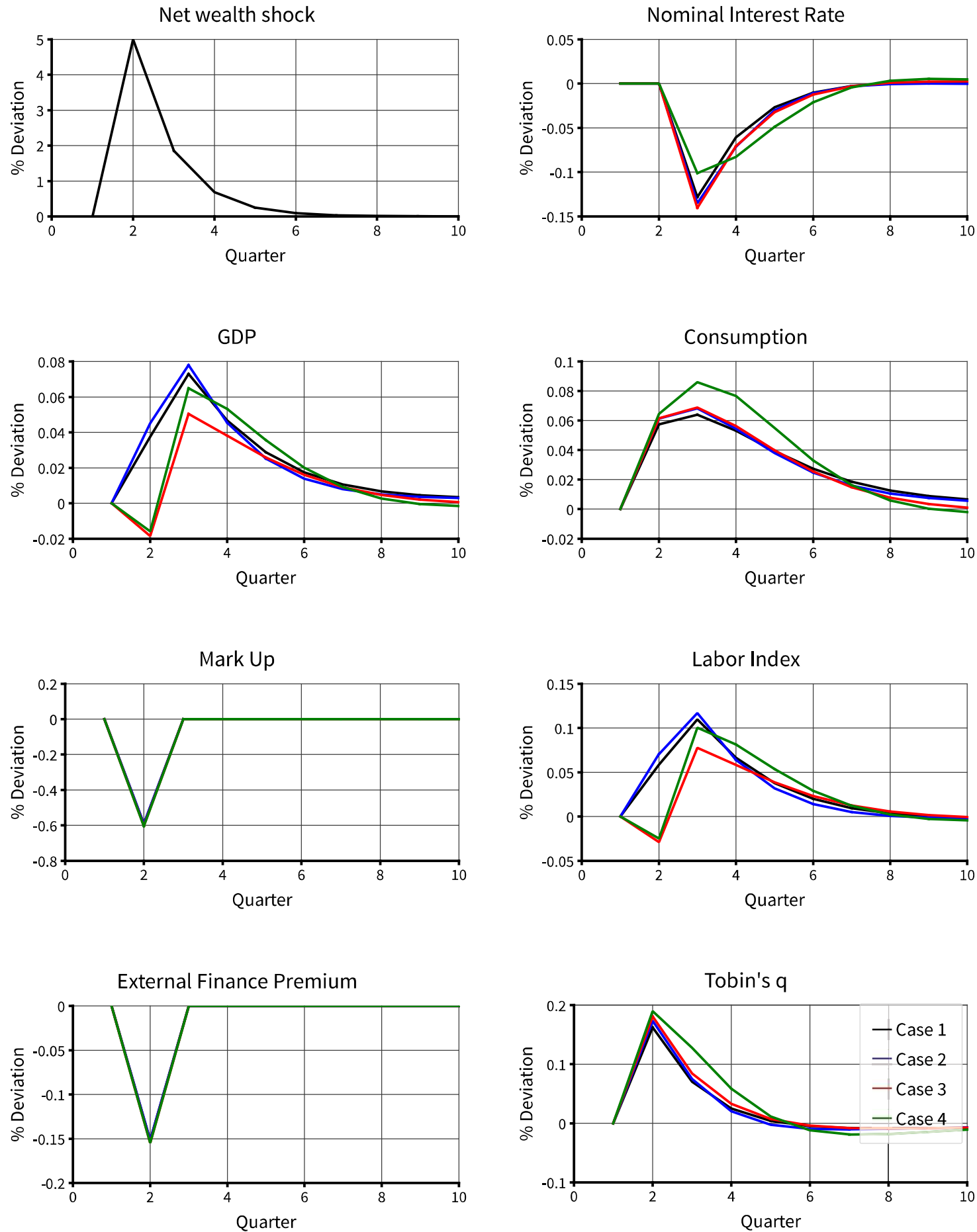

Fig. 5 Impulse responses to a financial shock. Notes: Case 1 (2) refers to the model with $\zeta=0.5$ and the simple (optimal) Taylor rule. Case 3 (4) refers to the model with $\zeta=2.5$ and the simple (optimal) Taylor rule 
Table 5 Welfare effects in the model with an additional financial shock

\begin{tabular}{lcc}
\hline & $\zeta=0.5$ & $\zeta=2.5$ \\
\hline$\vartheta_{1}$ & 0.30 & 0.63 \\
$\vartheta_{2}$ & 1.95 & 1.06 \\
$\vartheta_{3}$ & 0.02 & 0.01 \\
$\vartheta_{4}$ & 0.60 & 0.38 \\
$\lambda$ & -0.0734 & 0.0329
\end{tabular}

$\zeta$ is the elasticity of Tobin's q with respect to the investment-capital ratio $I$ / $K . \vartheta_{i}, i=1,2,3,4$ denote the coefficients of the Taylor rule (2.32) on the past interest rate, the inflation gap, the price of capital, and the output gap, respectively. $\lambda$ is the percentage of consumption that must be given (taken if positive) to the household in the pure inflation target regime with $\vartheta_{2}=1.5$ and $\vartheta_{i}=0, i=1,3,4$, to make him equally well-off as under the rule specified in columns i-iv

wages increase triggering a positive response of hours, output, consumption, and investment (see Fig. 5). The latter, in turn, increases Tobin's q. In the case of small adjustment costs of capital, $\zeta=0.5$, these effects occur immediately, whereas in the case of high adjustment costs, $\zeta=2.5$, labor supply and output drop in the impact period of the shock and increase thereafter. While similar in their effects on consumption, labor supply, and Tobin's q, the direct impact of a TFP shock has much larger effects than the indirect effect of a wealth shock, even though the latter is much larger in size $\left(\sigma_{Z}=0.0064\right.$ versus $\left.\sigma_{\xi}=0.05\right)$. Since both the TFP and the net wealth shock have similar effects (for the former, see Fig. 2 in the main text) so that the coincidence of a positiv TFP shock and a negative wealth shock dampens the reaction on Tobin's q, the central bank does not gain from targeting Tobin's q in addition to inflation and the output gap. Table 5 confirms this intuition.

In the case of small adjustment costs of capital, $\zeta=0.5$, the fine tuned Taylor rule aggressively increases the interest rate in response to inflation and the output gap. In the case of high adjustment costs, $\zeta=2.5$, where the effects of a TFP shock on output occur more gradually, the central bank changes its interest rate more cautiously (see also the upper right panel of Fig. 5).

\section{References}

Basu, S., \& Bundick, B. (2012). Uncertainty shocks in a model of effective demand. In NBER working paper. No. 18420.

Bernanke, B. S., \& Gertler, M. (1999). Monetary policy and asset price volatility. Economic Review, Federal Reserve Bank of Kansas City, Quarter IV, 17-51.

Bernanke, B. S., \& Gertler, M. (2001). Should central banks respond to movements in asset prices? American Economic Review, 91(2), 253-257.

Bernanke, B. S., Gertler, M., \& Gilchrist, S. (1999). The financial accelerator in a quantitative business cycle framework. In J.B. Taylor \& M. Woodford (eds.), Handbook of macroeconomics, Volume 1C. pp. 1341-1393. North-Holland: Amsterdam.

Bullard, J., \& Mitra, K. (2002). Learning about monetary policy rules. Journal of Monetary Economics, 49(6), 1105-1129. 
Calvo, G. A. (1983). Staggered prices in a utility-maximizing framework. Journal of Monetary Economics, 12, 383-98.

Carlstrom, C. T., \& Fuerst, T. S. (1997). Agency costs, net worth, and business fluctuations: A computable general equilibrium analysis. American Economic Review, 87, 893-910.

Carlstrom, C. T., \& Fuerst, T. S. (1998). Agency costs and business cycles. Economic Theory, 12, 583-597.

Carlstrom, C. T., \& Fuerst, T. S. (2007). Asset prices, nominal rigidities, and monetary policy. Review of Economic Dynamics, 10, 256-275.

Chari, V. V., Kehoe, P. J., \& McGrattan, E. R. (2009). New Keynesian models: Not yet useful for policy analysis. American Economic Journal: Macroeconomics, 1(1), 242-266.

Christiano, L. J., Eichenbaum, M., \& Evans, C. L. (2005). Nominal rigidities and the dynamic effects of a shock to monetary policy. Journal of Political Economy, 113, 1-45.

Christiano, L. J., Eichenbaum, M. S., \& Trabandt, M. (2015). Understanding the great recession. American Economic Journal: Macroeconomics, 7, 110-167.

Christiano, L., Ilut, C., Motto, R., \& Rostagno, M. (2010). Monetary policy shocks and stock market booms. In Proceedings-Economic policy symposium. Federal Reserve Bank of Kansas City: Jackson Hole. pp. 85-145.

Cúrdia, V., \& Woodford, M. (2016). Credit friction and optimal monetary policy. Journal of Monetary Economics, 84, 30-65.

Chugh, S. K. (2013). Costly external finance and labor market dynamics. Journal of Economic Dynamics and Control, 37, 2882-2912.

Epstein, L. G., Farhi, E., \& Strzalecki, T. (2014). How much would you pay to resolve long run risk? American Economic Review, 104(9), 2680-2697.

Epstein, L. G., \& Zin, S. (1989). Substitution, risk aversion and the temporal behavior of consumption and asset returns: A theoretical framework. Econometrica, 57, 937-969.

Erceg, C. J., Henderson, D. W., \& Levin, A. D. (2000). Optimal monetary policy with staggered wage and price contracts. Journal of Monetary Economics, 46, 281-313.

Faia, E., \& Monacelli, T. (2007). Optimal interest rate rules, asset prices, and credit frictions. Journal of Economic Dynamics and Control, 31, 3228-3254.

Gale, D., \& Hellwig, M. (1985). Incentive-compatible debt contracts: The one-period problem. Review of Economic Studies, 52, 647-664.

Gilchrist, S., \& Saito, M. (2008). Expectations, asset prices, and monetary policy: The role of learning. In J. Y. Campbell (Ed.), Asset prices and monetary policy (pp. 45-102). Chicago: University of Chicago Press.

Gourio, F. (2012). Disaster risk and business cycles. American Economic Review, 102(6), 2734-2766.

Hall, R. E. (1997). Macroeconomic fluctuations and the allocation of time. Journal of Labor Economics, 15(1), S223-S250.

Jermann, U. J. (1998). Asset pricing in production economies. Journal of Monetary Economics, 41, 257-275.

Lütkepohl, H. (2005). New introduction to multiple time series analysis. Berlin: Springer.

Machado, V. D. G. (2012). Monetary policy and asset price volatility. In Working Paper Series, Banco Central do Brasil. No. 274.

Mimir, Y. (2016). Financial intermediaries, credit shocks and business cycles. Oxford Bulletin of Economics and Statistics, 78(1), 42-74.

Nakajima, T. (2005). A business cycle model with variable capacity utilization and demand disturbances. European Economic Review, 49, 1331-1360.

Schmitt-Grohé, S., \& Uribe, M. (2004a). Solving dynamic general equilibrium models using a secondorder approximation to the policy function. Journal of Economic Dynamics and Control, 28, 755-775.

Schmitt-Grohé, S., \& Uribe, M. (2004b). Optimal operational monetary policy in the ChristianoEichenbaum-Evans model of the US business cycle. In Centre for Economic Policy Research (CEPR) discussion paper No. 4554.

Schmitt-Grohé, S., \& Uribe, M. (2005). Optimal fiscal and monetary policy in a medium-scale macroeconomic model: Expanded version. In National Bureau of Economic Research (NBER) Working Paper, No. W11417.

Schmitt-Grohé, S., \& Uribe, M. (2007). Optimal simple and implementable monetary and fiscal rules. Journal of Monetary Economics, 54, 1702-1725. 
Swanson, E. T. (2012). Risk aversion and the labor margin in dynamic equilibrium models. American Economic Review, 102(4), 1663-1691.

Taylor, J. B. (1993). Discretion versus policy rules in practice. Carnegie-Rochester Conference Series on Public Policy, 30, 195-214.

Townsend, R. M. (1979). Optimal contracts and competitive markets with costly state verification. Journal of Economic Theory, 21, 265-293.

Williamson, S. D. (1987). Costly monitoring, optimal contracts, and equilibrium credit rationing. Quarterly Journal of Economics, 102, 135-145. 